\title{
Reanalysis and Re-evaluation of Geochemical Data of Central Basin of Republic Democratic of Congo
}

\author{
Romulus Mawa Tuzingila ${ }^{1}$, Ruben Koy Kasongo ${ }^{2}$, Emmanuel Kalemba ${ }^{1}$, Kelly Nzambe ${ }^{1}$, Joel Kabesa \\ Kilungu $^{1}$, Alain CIBUMBA CIBUMBA ${ }^{1}$ \\ ${ }^{1}$ Faculty of Oil, Gas and New Energies, Department of Exploration and Production, University of Kinshasa, \\ RD Congo \\ ${ }^{2}$ Faculty of Science, Department of Geosciences, University of Kinshasa, RD Congo
}

\begin{abstract}
In order to revalue hydrocarbons in the central Basin, the present study milked on the reinterpretation and the réanalyse of the geochemical data of the central Basin. It extracts these data of the well from Samba and Dekese, by their carrots preserved at the museum royal of central Africa about the Fifties. It réanalyse and reinterprets their respective bed rocks to come out from it the quality of hydrocarbon by pyrolysis rock'n'roll-eval. The first interpretation of these data was already made in 2012 but used only three diagrams of first generation of rock'n'roll-eval VI. This work as for him uses ten various diagrams lately set up of pyrolysis rock'n'roll-eval VI in order to criticize the first interpretations emphasized from it the true oil interest of these two localities with more succeeded details.

Software such as OasisMontaj, ArcGIS and Excel made it possible to recreate the ten diagrams to incorporate the data of rock'n'roll-eval VI in it, in order to draw a more faithful interpretation from it. This exercise will thus make it possible to have a precision on the locality having mature organic matter in order to consider work more detailed in the central Basin.
\end{abstract}

Keywords: Geochemical Data, Reinterpretation, pyrolysis rock'nroll-eval VI.

\section{INTRODUCTION}

Regarded as a geological scandal, the Democratic Republic of Congo (RDC) is certainly counted among the countries potentially rich in hydrocarbons knowing of the serious problems with regard to the exploitation of their layers. The Democratic Republic of Congo has three large sedimentary Basins, namely:the coastal Basin, the Basin of Rift-is African and the Basin of the central Basin. Of all these Basins, only the coastal Basin is currently in exploitation.

The Basin of the central Basin represents an enormous challenge because of its surface and the insufficiency of the data which push many investors to reflect several times before beginning with exploration and the possible production of the layers of this Basin.

The present study has like objectives, to contribute to the priorisation and valorization of future work of exploration and possibly oil production within the central Basin, then to justify the resumption of work of exploration in this area; In order to look further into knowledge in the sector of hydrocarbons of the basin of the central basin. We chose the localities of Samba and Dekese where two stratigraphic wells were produced in the years 1950 without truly seeking a certain oil interest.

Indeed, on the basis of the bibliographical information collected and preexistent documents on the oil geology of the central basin, it was shown that the organic matter presents in the bed rock of Samba or of Dekese reached a pronounced maturity, which will make it possible to foresee research more thorough of oils in these surroundings; Thus, the central Basin being a giant oil layer not yet exploited, one can of this fact of starting again the search of hydrocarbons in this basin thanks to the geochemical data obtained of the well of Samba and that of Dekese by the process of pyrolysis rock'n'roll-eval 6 .

However, of the samples of carrots were taken, preserved and analyzed by the first generation of pyrolysis Rock'n'roll-eval VI in 1988 and 2012 (knows and Al, 2012), which a certain interpretation left.

Today, there are several types of specific diagrams which could lead to analyses and interpretations more refined and more led in order to arise the true oil interest of these two localities. This exercise will thus make it possible to consider future work with more precise interpretations. Thus the oil blocks could be allotted in knowledge of the causes. 
The Central Basin is located in equatorial Africa and extends on a surface moreover $1.400 .000 \mathrm{~km} 2$, mainly in the Democratic Republic of Congo where it occupies nearly $800.000 \mathrm{~km} 2$ [20].

The central Basin congolaise, the Inner basin of Zaire and the Congolais Basin are all the terms used in the literatures which describe (Kadima and Al, 2011) the vastness and the great longevity of the intracratonic depression (intracontinentale) of central Africa as presented in figure 1 .

It starts with the periphery of the province of Kinshasa and passes by the provinces of the South-Ubangi, North-Ubangi, Mongala, of Ecuador, of Tshuapa, Maï-Ndombe, Sankuru, Kasai, Tshopo, Kwilu, Kwango, Lulua, of Kasaï-Eastern, part of Bas-Uele, Maniema, Lomami, with a sedimentary continuity in Congo-Brazzaville and Sudan.
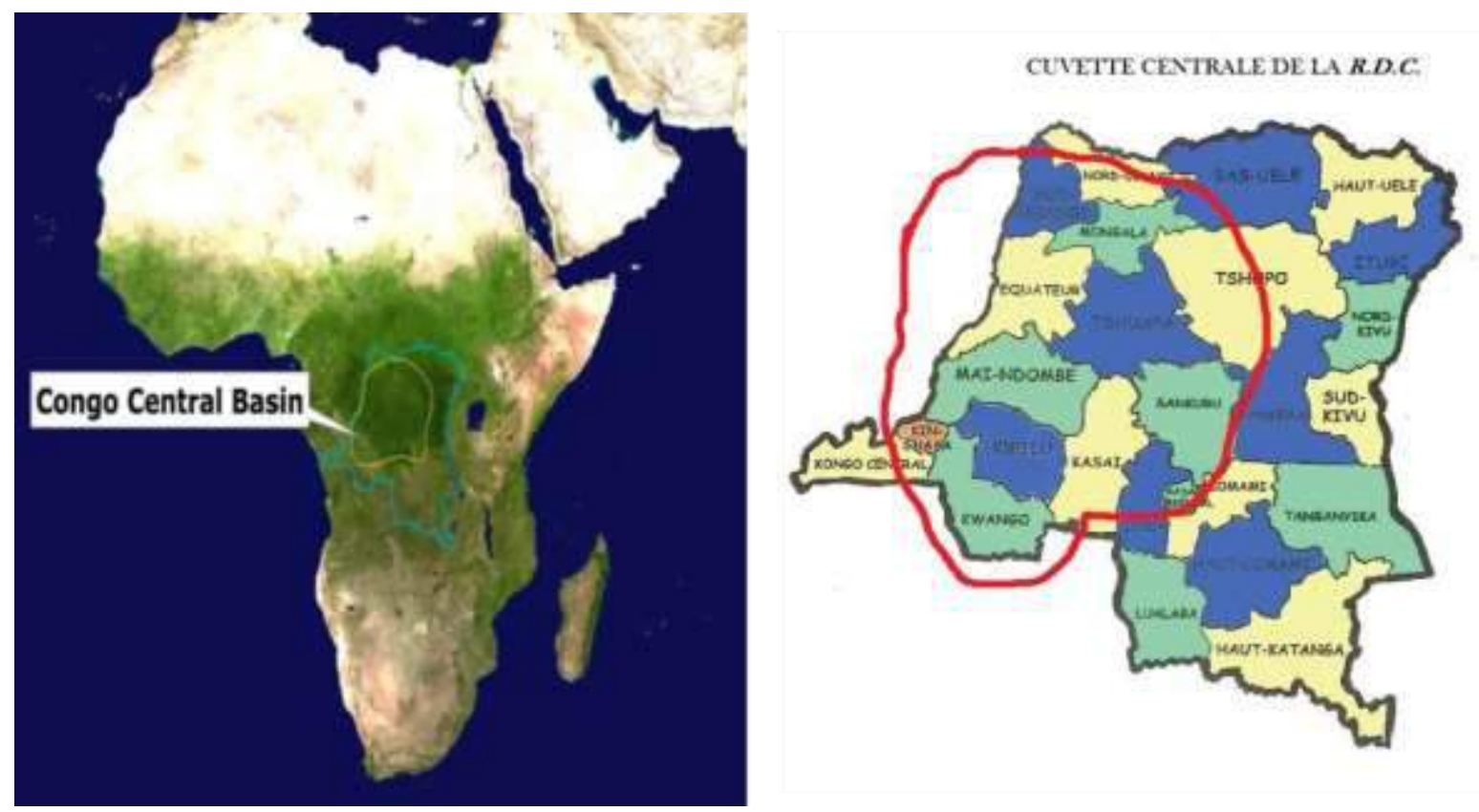

Figure 1: Localization of the central Basin (Pili pili, 2010)

In the part is, its limit is erosion and forms the Western shoulder of the System of East-African ditches.

Four principal under-Basins are recognized in the central Basin of Congo:the under-Basin of Busira of the North-East and the under-Basin of Lomani, under Lindien Basin of the North-East and under central Basin of Lokoro.These under-Basins are separated by three high funds:Inongo, Kiri and Lonkoni.

But one counts seven under-Basin in all:the under-Basin of Busira, the under-Basin of Lindien, the under-Basin of Lokoro, the sousBassins of Lomami, the under-Basin of Busira, the under-Basin of Kwango, under-Basins of the West-Congolien.(PiliPili, 2010).

Although oil potential of approximately 1.2 Million $\mathrm{km}^{2}$ of the Basin intracontinental was of interest since decades (Misser, 2013), the Basin of Congo east always one of largest, well-known in the world.

Thus, the stratigraphic wells of Dekese and Samba were drilled in the years 1950 (figure 2).They was wells completely cored with a good recovery of $84 \%$ and $78 \%$ respectively (Cahen and Al, 1959 and 1960), representing the single stratigraphic sections in the center of the central Basin.All the carrots of these two wells were stored in Tervuren with the MRAC. 


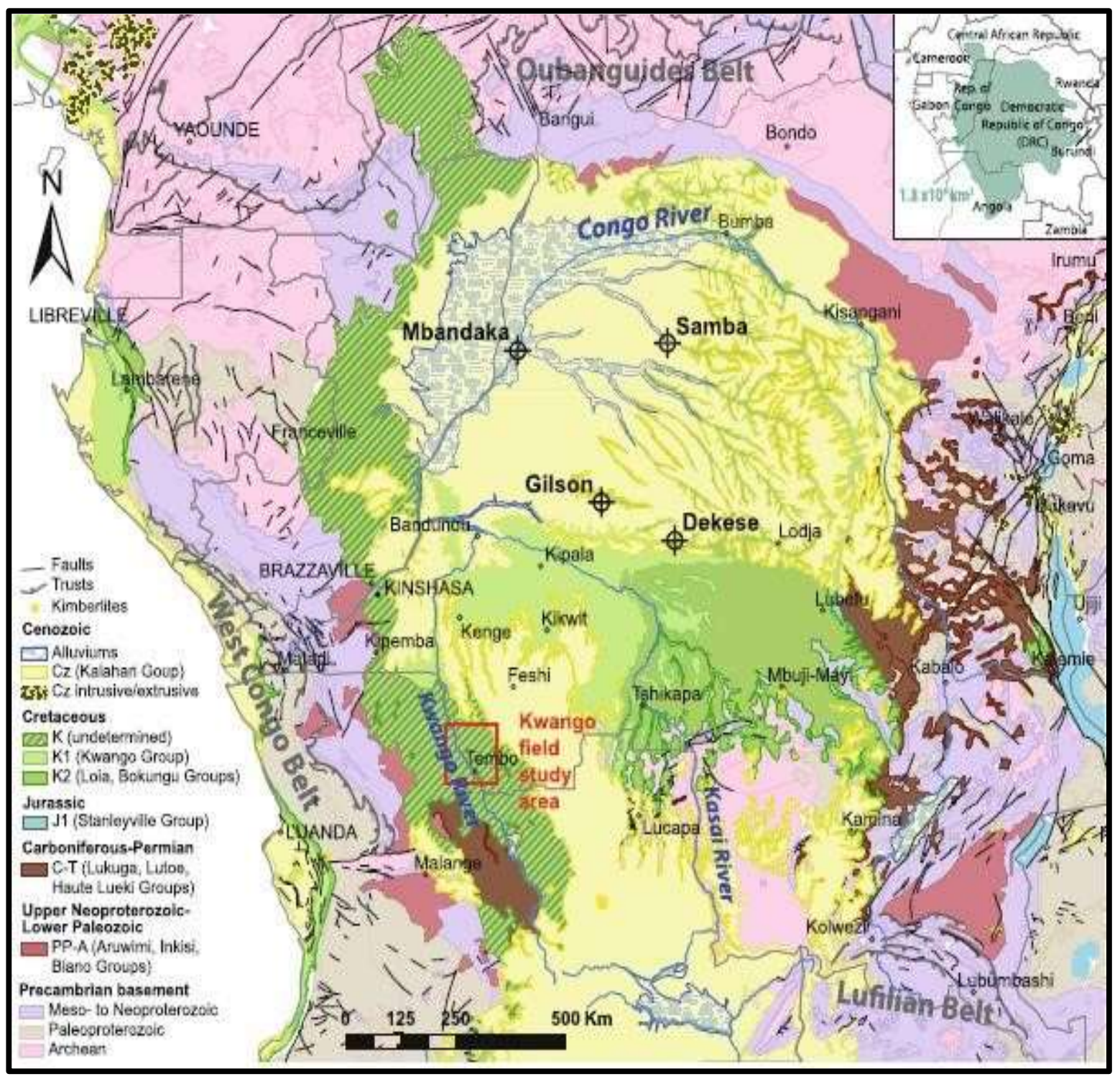

Figure 2: Localization of the wells of the central Basin

The well of Samba is located at 009' 45' ' N and 2115' 10 " E, along the Maringa river, in the north-eastern part of the central Basin.It crosses $1167 \mathrm{~m}$ of the sandstones and red mudstones lities to greens subhorizontaux (S1 units in S5, figure 3), then 871 $\mathrm{m}$ thickness of sandstone quarzites (S6 unit). The well stops with the $2038 \mathrm{~m}$ depth and did not reach the base of the quarzites (3) (D.Delvaux figure, 2001).

The well of Dekese is located at 327' $26^{\prime}$ ' S and 2124' 28' ' E, to $400 \mathrm{~km}$ in the south of the well of Samba, in the southern central part of the Basin.It crosses $755 \mathrm{~m}$ thickness dominated by subhorizontaux red sandstones (D1 units in D6), then $962 \mathrm{~m}$ thickness of the black shales and diamictites slightly deformed (D7 with D9). This section also rests on a base of the red sandstones quartzitic (D10 unit).The well stops with the $1856 \mathrm{~m}$ depth and does not reach the base of the quarzites (figure 3).(D.Delvaux, 2001) 


\section{Dekese (core)}

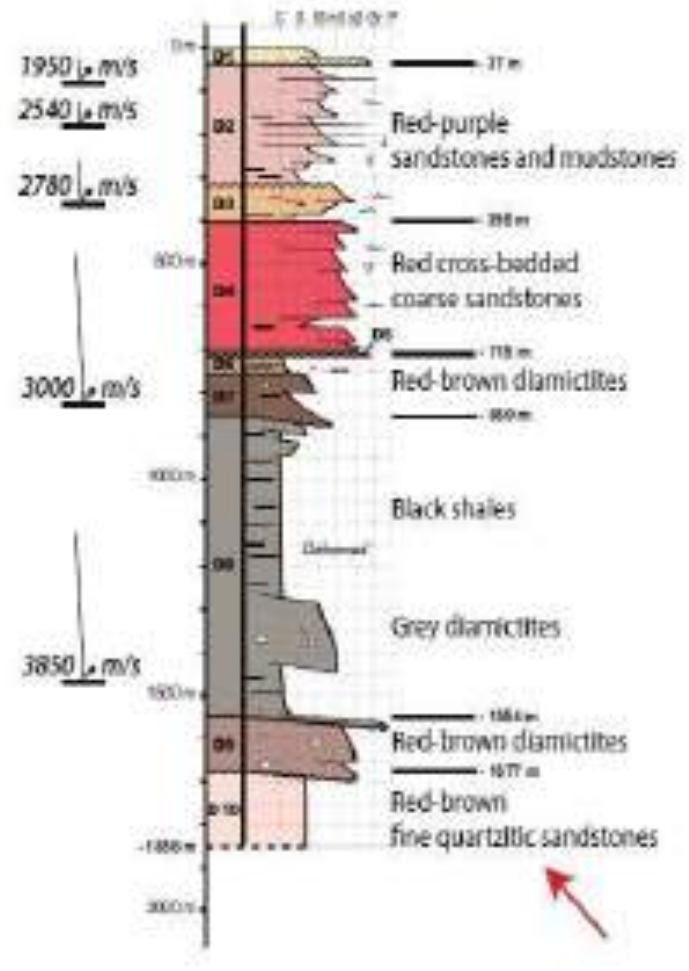

\section{Samba (core)}

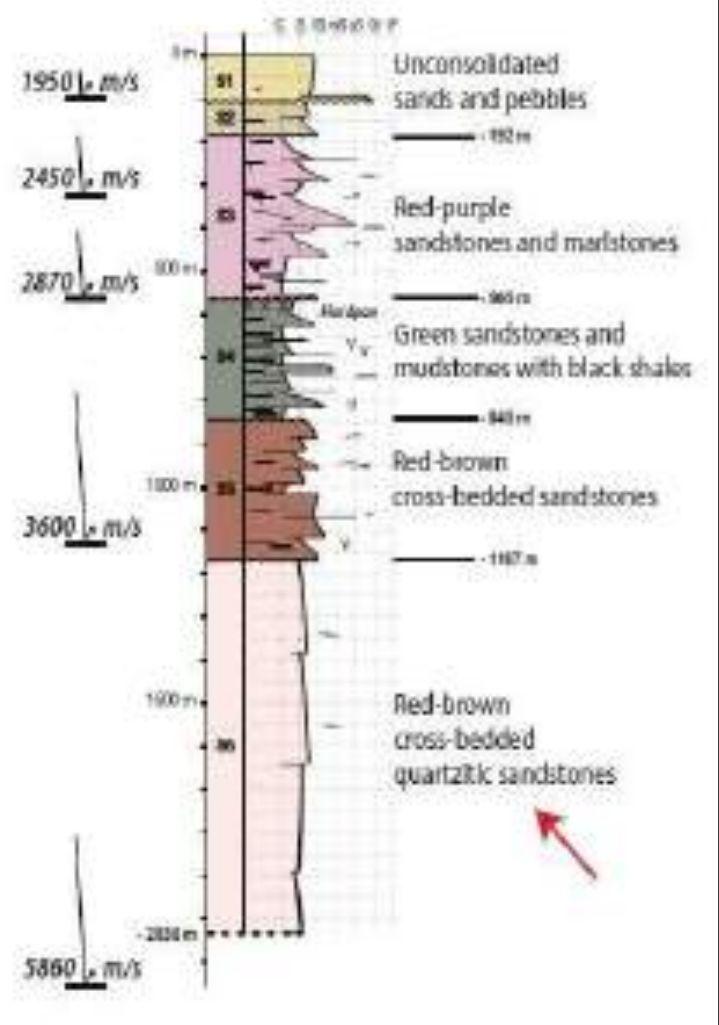

Figure 3: Stratigraphic column of the wells of Samba and Dekese

Rising of seismic refraction dating between 1950 and 1956 primarily determined the thicknesses of the sediments with various localizations (111 stations) through the central Basin. The depths of various seismic discontinuities were calculated at each station, and because the sedimentary sets were considered largely tabular and horizontal swiftnesses higher than the vertical swiftnesses. The geological units were thus systematically given.

A seismic profile of refraction $850 \mathrm{~km}$ length crossed the sections of Samba and Dekese and could identify five distinct seismic units corresponding to the stratigraphic units in the two wells (figure 4 and figure 5):

- The unconsolidated materials surface $(<2200 \mathrm{~m} / \mathrm{s})$;

- Sandstone and mudstones poorly consolidated (3000 to $3600 \mathrm{~m} / \mathrm{s}$ );

- Black shales and diamictites (3 600 to $3900 \mathrm{~m} / \mathrm{s}$ ); Sandstone quarzites (4 200 to $4600 \mathrm{~m} / \mathrm{s}$ );

- Rocks of the base (> $5200 \mathrm{~m} / \mathrm{s})$. 


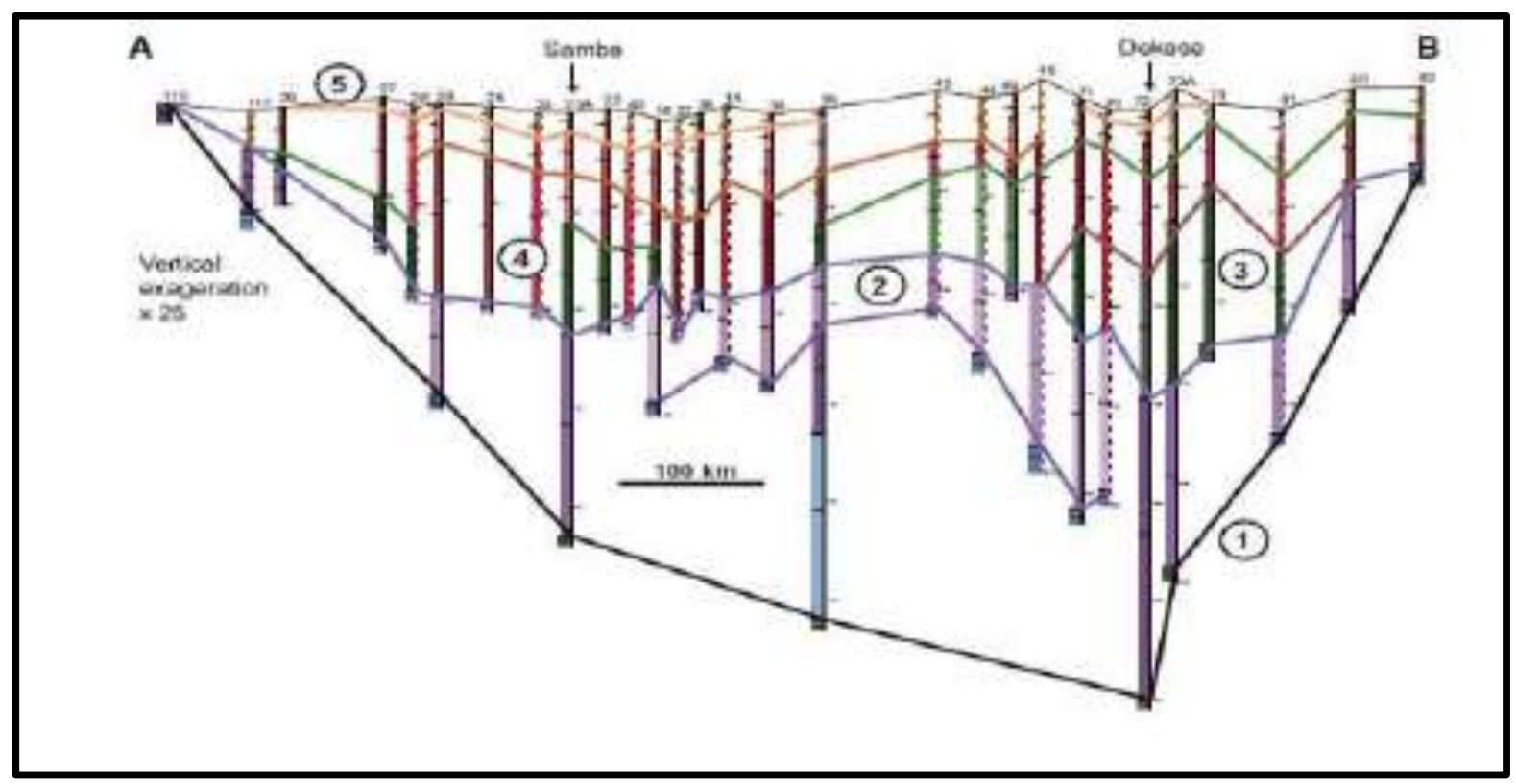

Figure 4: Stratigraphic sequences deduced from the seismic refraction

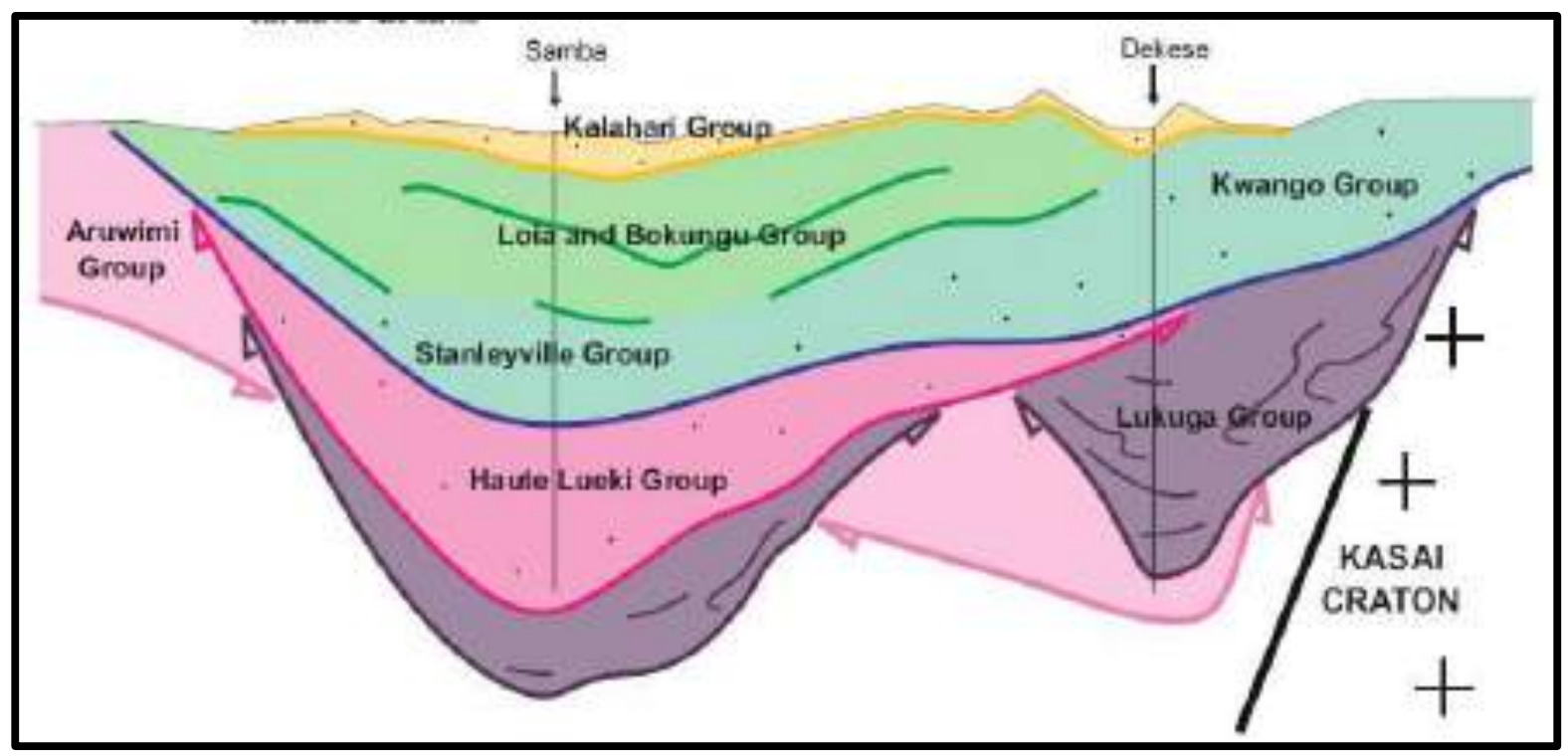

Figure 5: Interpretation of the stratigraphic sequences deduced from the seismic refraction

\section{MATERIEL AND METHOD}

\subsection{Material}

We were useful ourselves of a portable computer containing:Word, Excel, and the software Arc-Gis and Oasis for the stratigraphic logs.

\subsection{Methodology}

In order to achieve definite goals Ci-high and especially for good a réanalyse of data for a logical and coherent reinterpretation of these data, we made recourse to the methods and techniques analytical and documentary.To this end, several works on exploratory work of the central Basin were consulted.The réanalyse and the reinterpretation of the historical data were made by using new specific diagrams of pyrolysis Rock'n'roll-Eval. 


\section{RESULTS AND INTERPRETATION}

3.1. Description of geological and geochemical data of well SAMBA and DEKESE

\subsubsection{Geological data of well SAMBA and DEKESE}

On the basis of seismic, lithological and biostratigraphic analysis, attempts at correlation were carried out between the wells (figure 6,7,8,9).

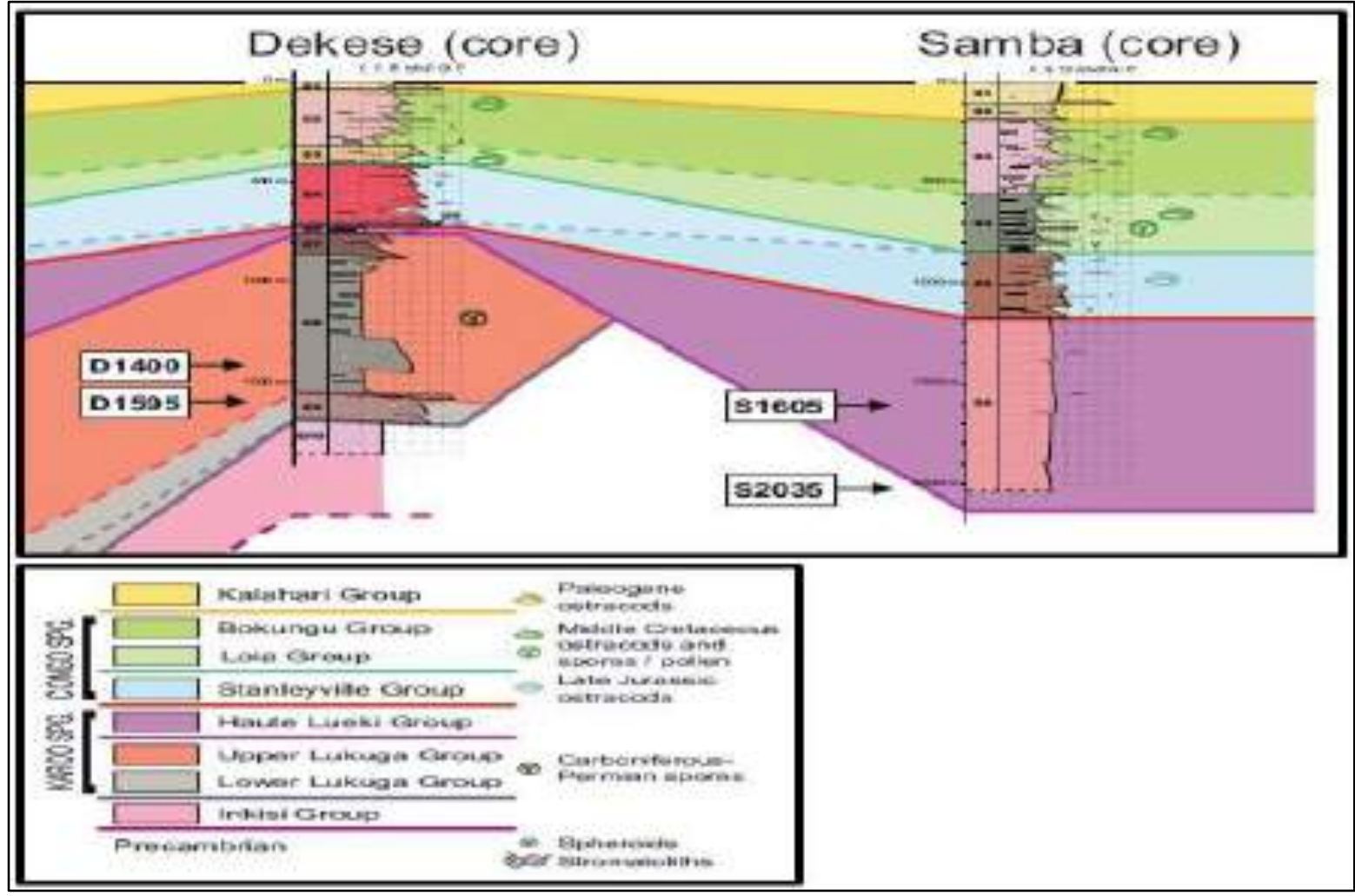

Figure 6: Correlation enters the wells of Dekese and Samba

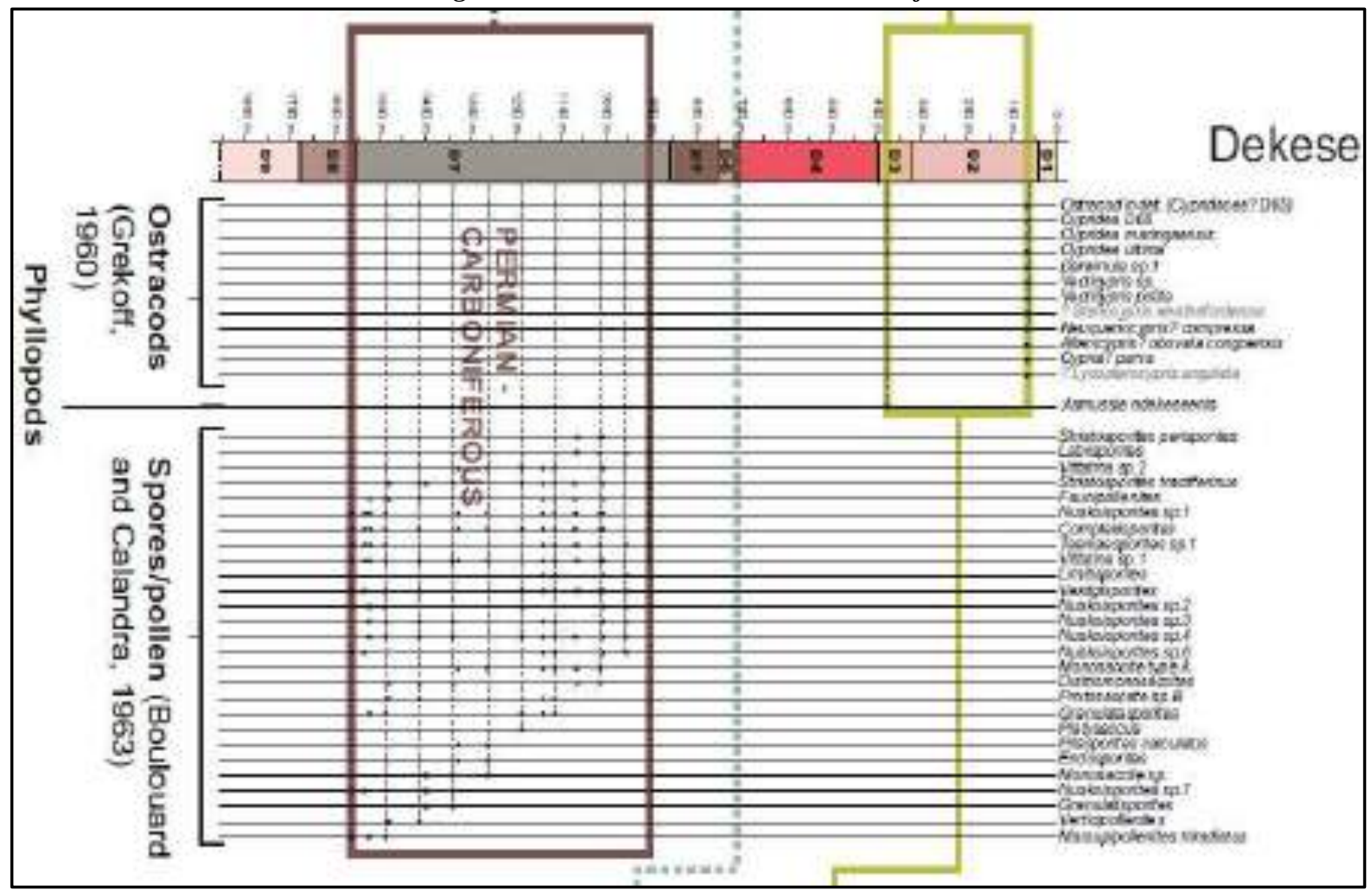

Figure 7: Fossils found in the well of Dekese 


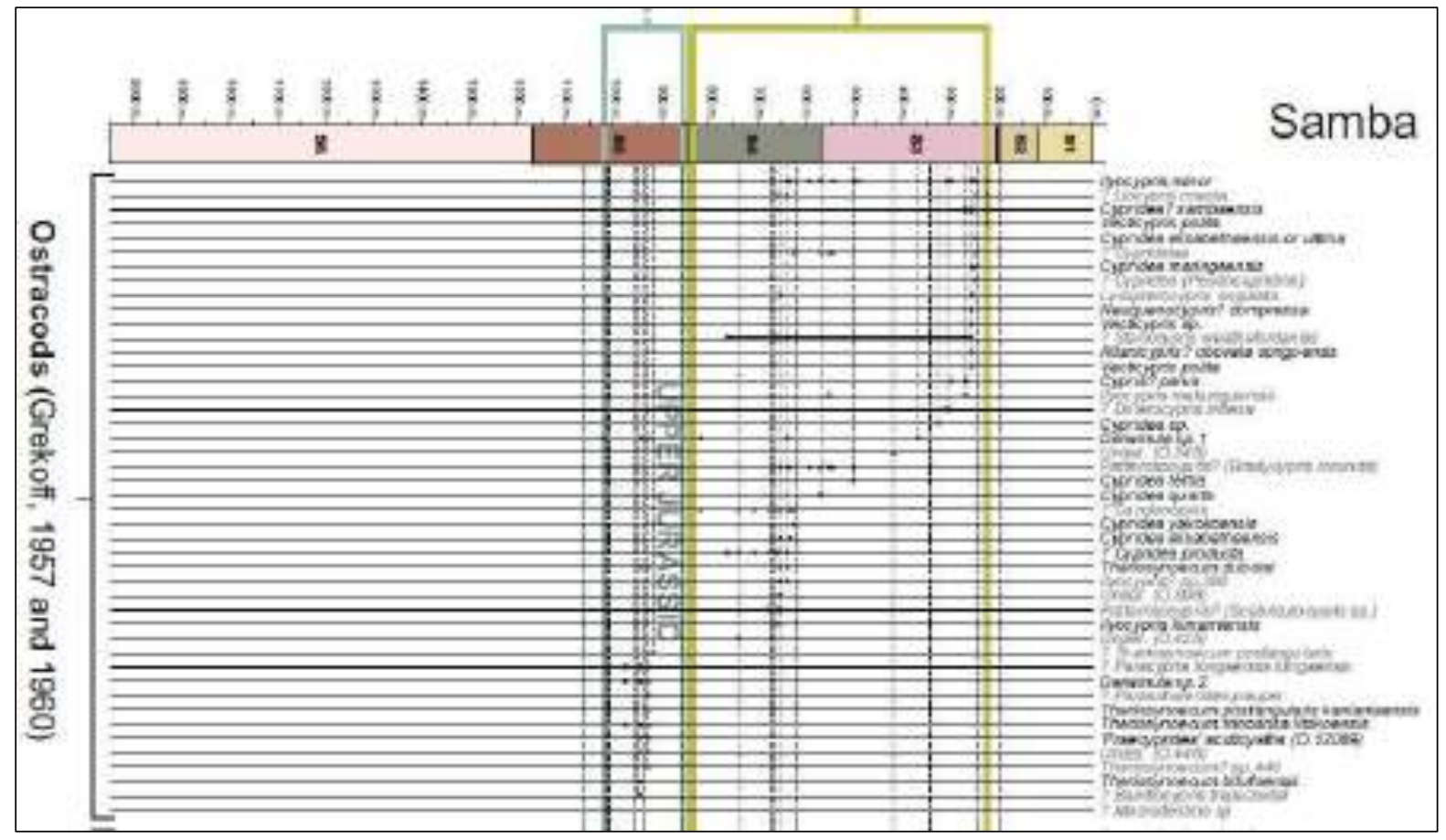

Figure 8: Fossils found in the well of Samba 


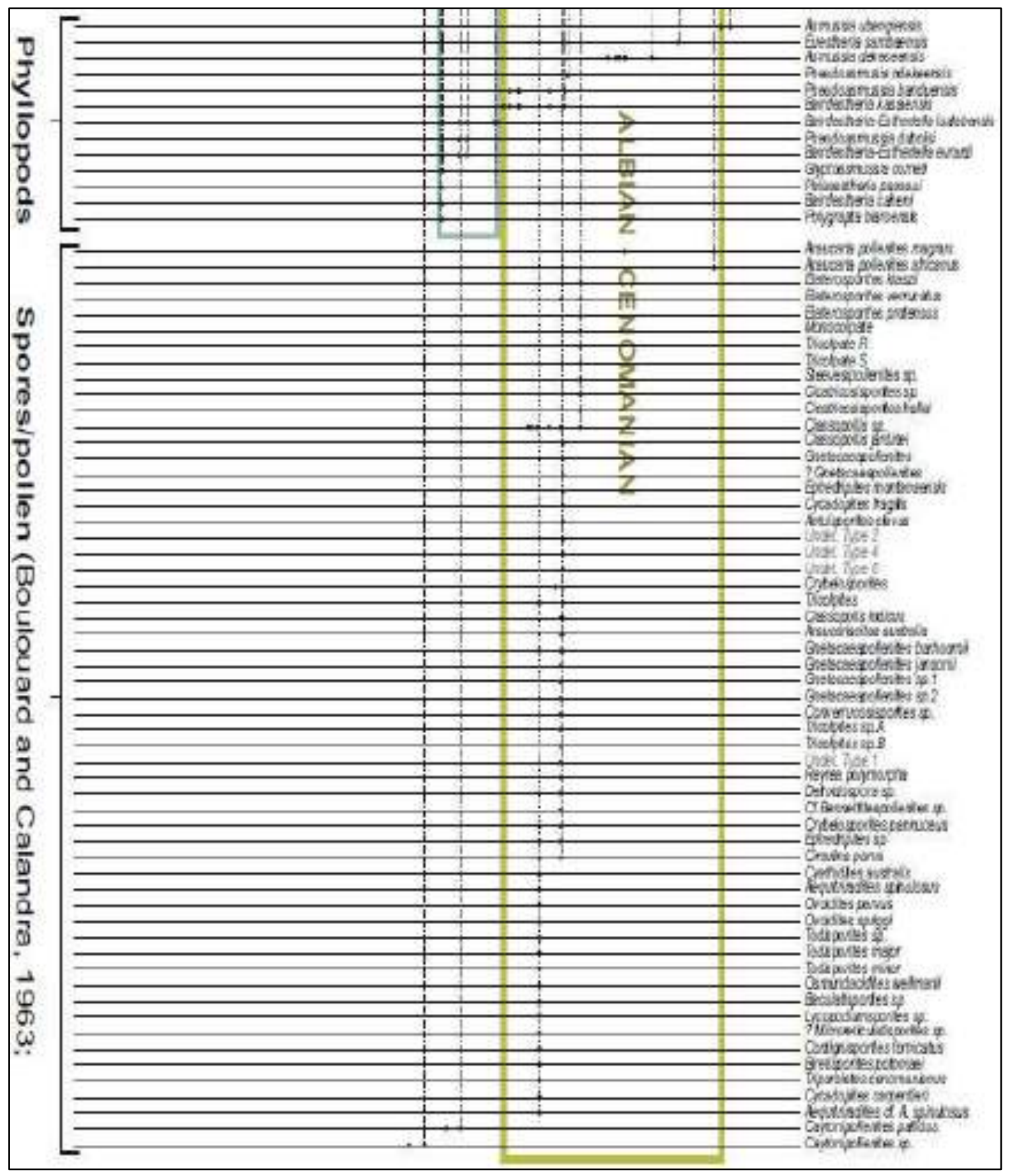

Figure 9: Fossils found in the well of Samba

The analysis of the facies at the bottom of the wells of Samba and Dekese arises from the possibilities of rock-mothers, tanks and cover potential such as the bioturbés black shales, sandstone and mudstones bioturbés interstratified of marine origin in Samba (figure 10), the coarse and ferruginous sandstones of wind origin in Dekese (figure 11), the successions of the lake perennial facies made sandstones heterolithic with carbonate fragments and intercalations of the black shales (figure 12) with Samba, the mudstones and marls carbonated as well as the fluviatile carbonated conglomerates with Samba (figure 13) and of the successions of the fluvio-deltaic facies including/understanding of mudstones and coarse sandstoneswith carbonated conglomerates with Dekese (figure 14). 
International Journal of Advances in Scientific Research and Engineering (ijasre), Vol 5 (8), August-2019

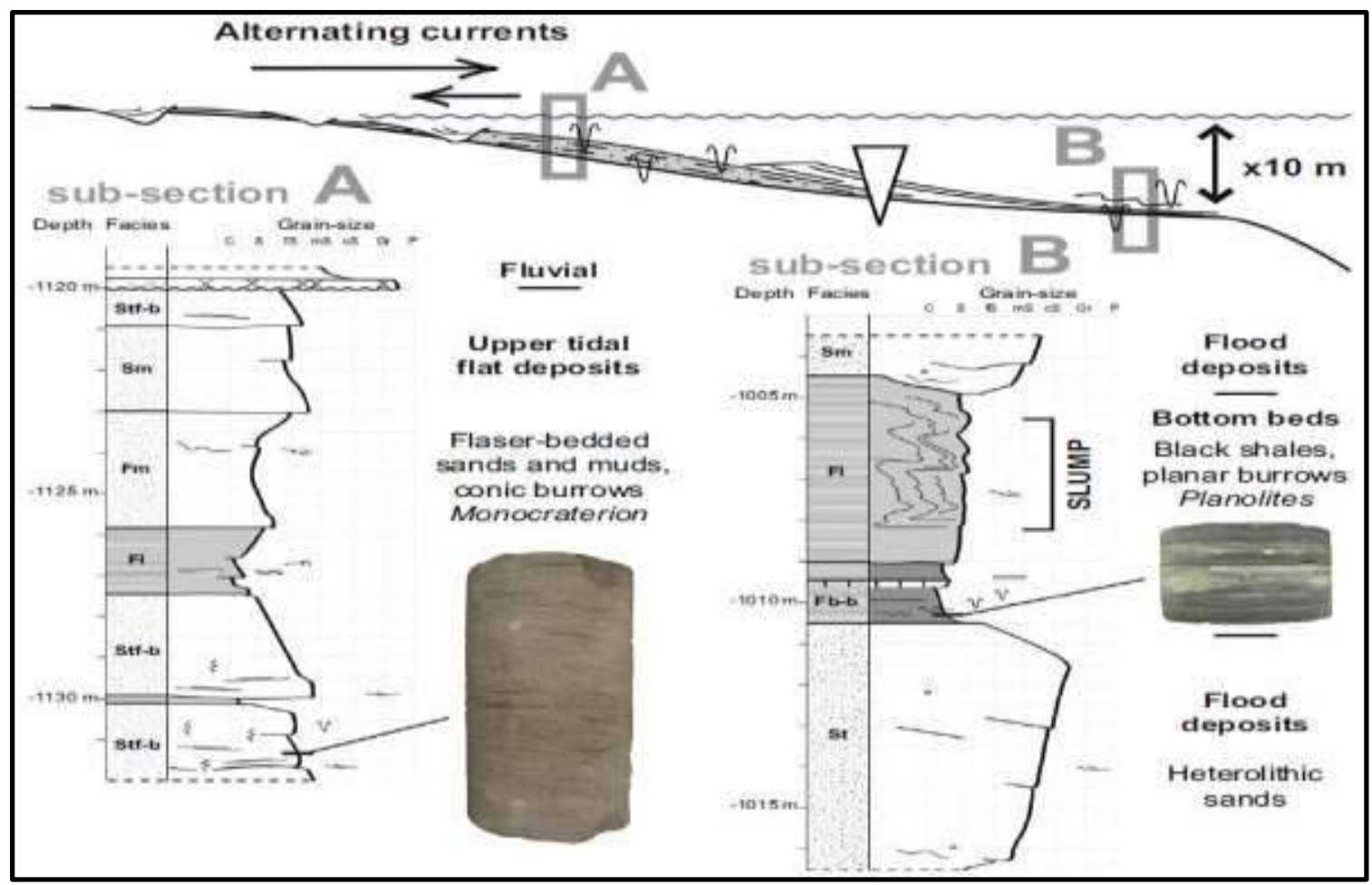

Figure 10: Marine facies of the sandstones, mudstones and shales black in the well of Samba

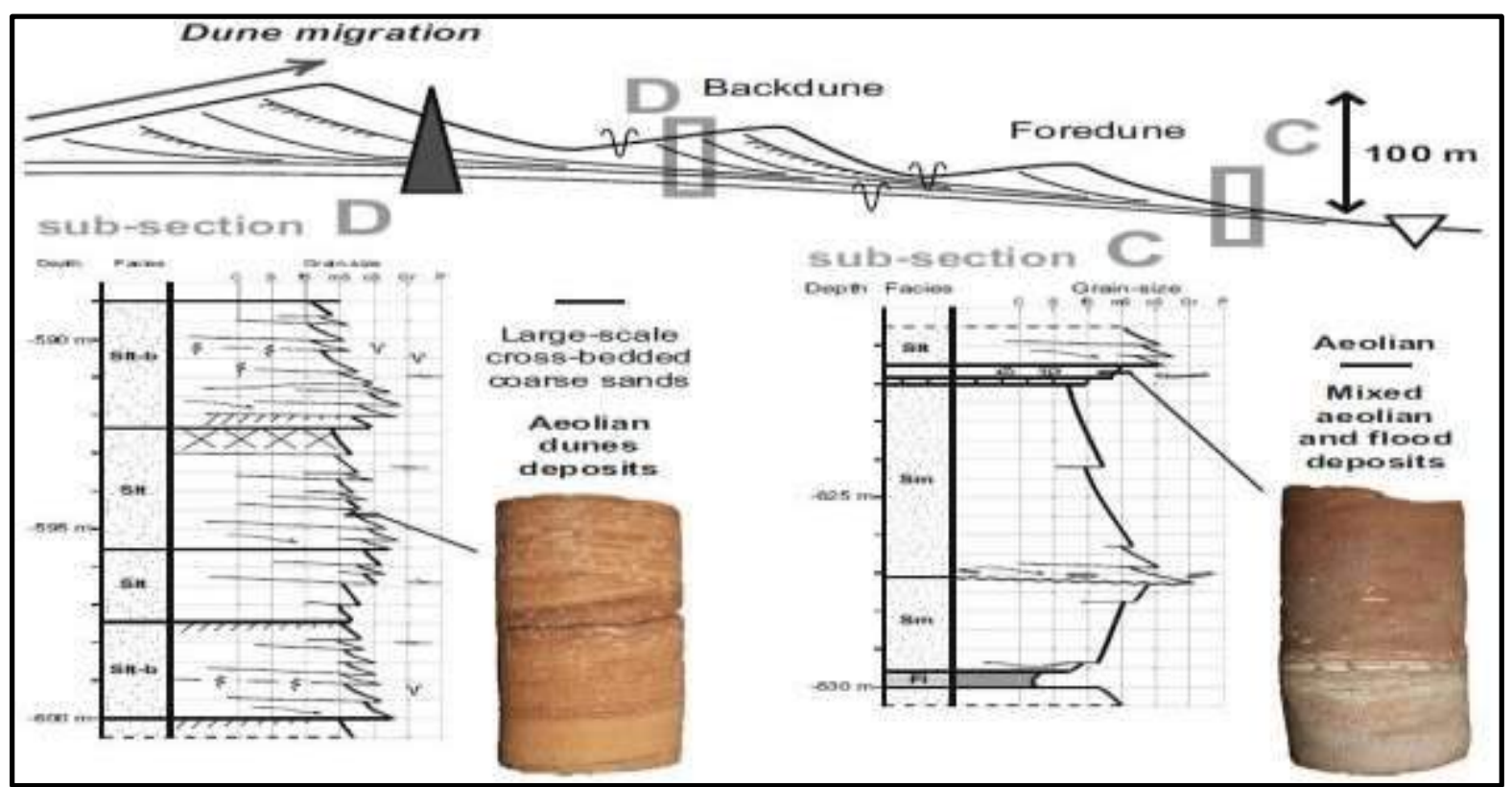

Figure 11: Wind facies of the coarse and ferruginous sandstones in the well of Dekese 
International Journal of Advances in Scientific Research and Engineering (ijasre), Vol 5 (8), August-2019

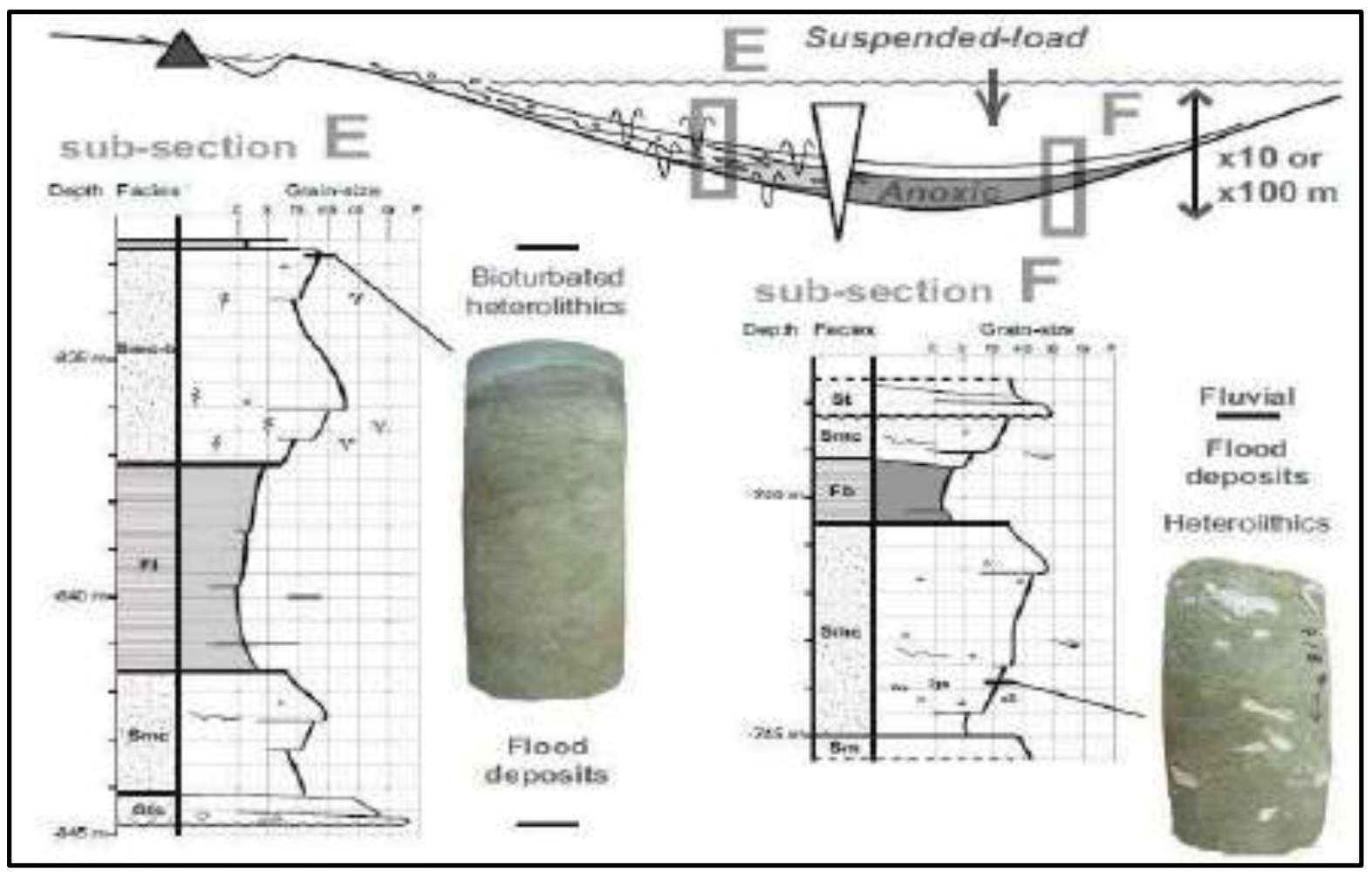

Figure 12: Sandstone facies lake heterolithic and carbonated in the well of Samba

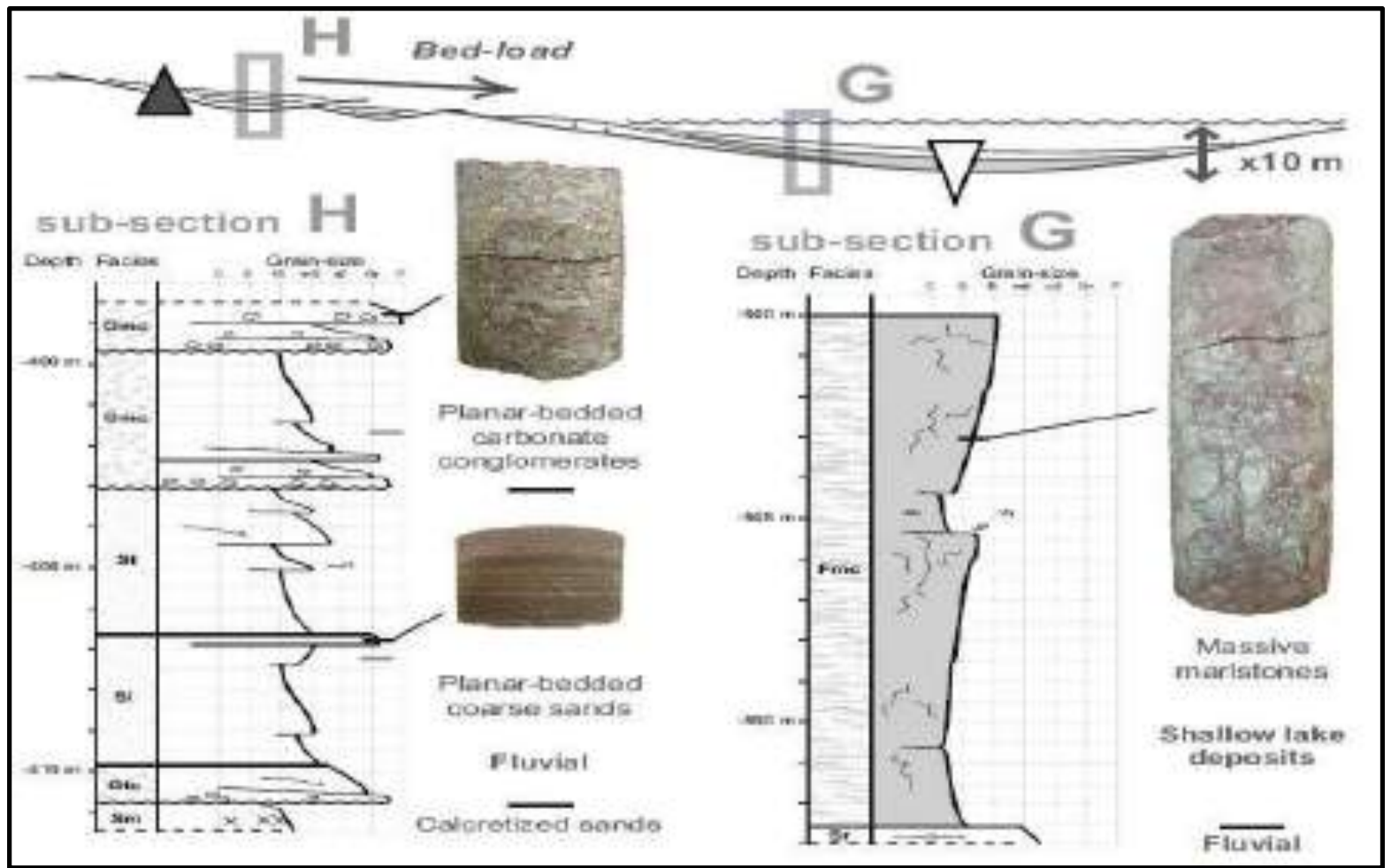

Figure 13:Semi-perennial lake facies of the carbonated conglomerates, coarse sandstones and massive marls in the well of Samba 


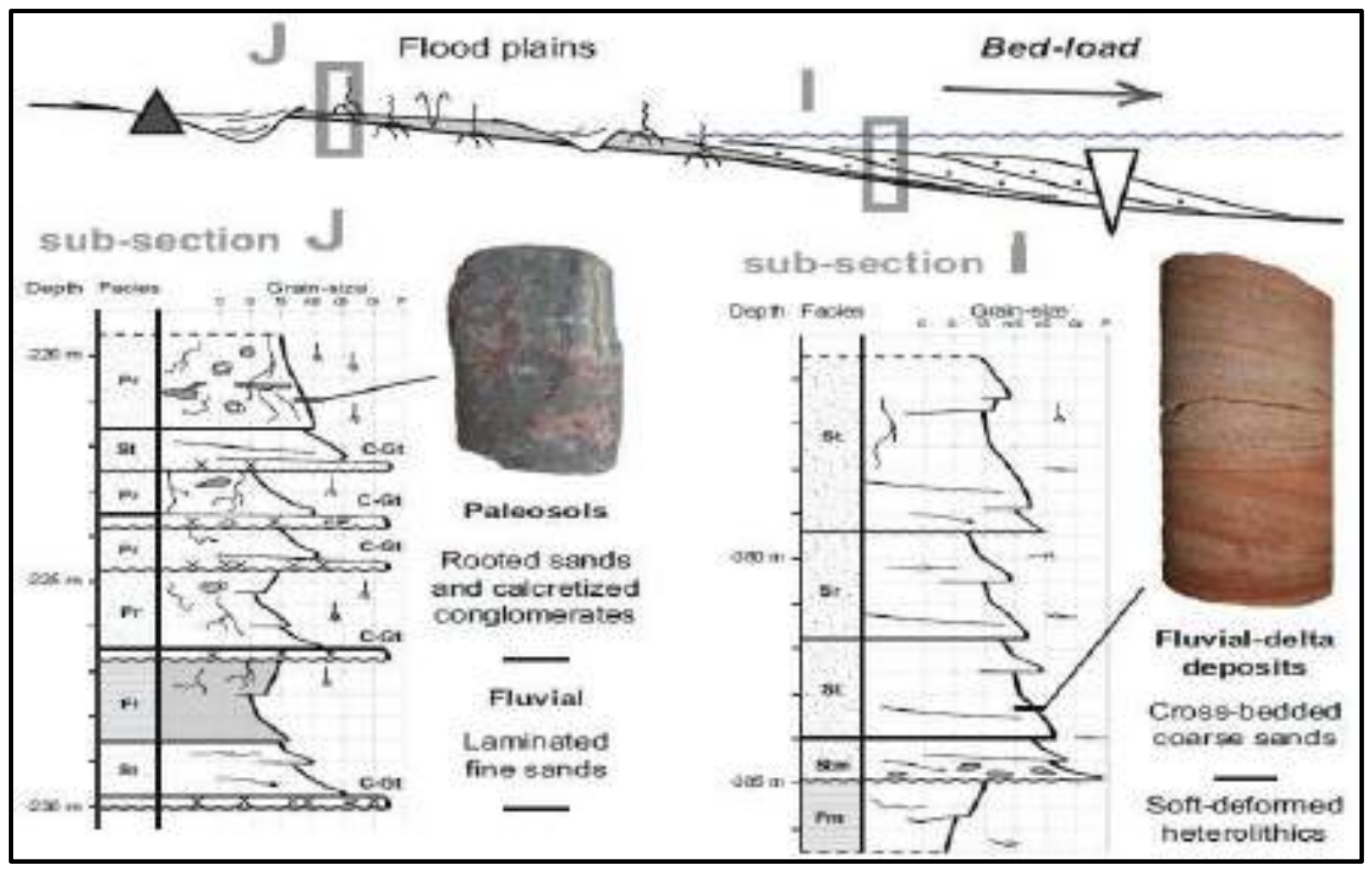

Figure 14: Marine facies of the sandstones, mudstones and shales black in the well of Dekese

\subsubsection{Geochemical data of well SAMBA and DEKESE}

The estimates of the oil potential and the maturity of these rock-mothers were initially based on a number limited of analyses of the organic matter starting from the selection of samples of carrots and outcrops stored to the Royal Museum of Africa Centrale.The first generation of instruments Rock'n'roll-Eval (RRI, 1988) was used for these analyses.The JNOC (National Japanese Oil Corporation) carried also out a certain number of analyses on separate samples of outcrops, mainly of the shales rich in organic matter of the group of Loia and Stanleyville, but was unable to relocate the samples on the charts.

New petrologic and geochemical analyses (RockEval and gas chromatography coupled with the spectroscopy of mass), were carried out by Sachse et al..(2012) on a great number of samples and carrots of Paleozoic and Mésozoïque of the wells of Samba and Dekese.

Thus, of the samples of well and outcrop were taken through the central Basin during several exploration campaigns. We considered only those taken in the wells of Samba and Dekese filed to the MRAC, on which we used several diagrams of interpretation.

Factors S1, S2, S3, Tmax, IH, IO, IP, PG, CP, S2/S3, Ro and COT were taken into account to evaluate the quantity, the type and the maturation of the organic matter contained in the rock-mothers of Samba and Dekese.

Briefly let us recall that, (Espitalie et al., 1985):

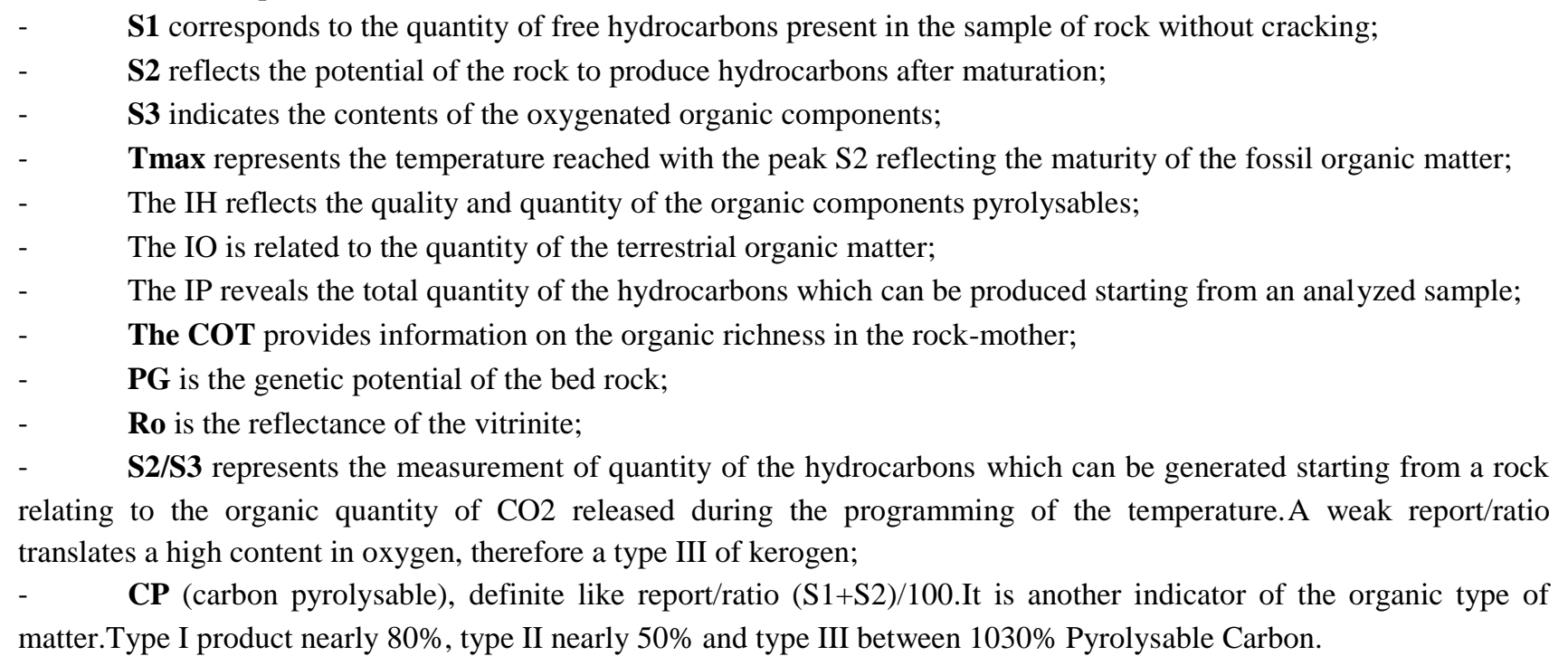


All these factors are indicative level of maturity of the organic Matter, types of Organic Matter and produced quantities of hydrocarbons or to produce starting from the analyzed rock-mother.

We will use diagrams in order to rejoin the possible theories to give a global vision is simpler evolution of the organic matter. Indeed, the well of Samba was sampled only in the interval of depth between $654 \mathrm{~m}$ and $825 \mathrm{~m}$, primarily in the bituminous shales sometimes with intercalations of the sandy or sandy shales, all of age cretacic, the group of Loïa (B.Linol, 2013).

The choice related to a sampling only in the bituminous shales could be justified by the possibility that they were formed in an environment anoxic, in absence of oxygen, bioturbations, benthic fauna and digger organizations. It is significant to recall that the bituminous shales are related to significant sources of hydrocarbons throughout the world.

A total of 13 samples was taken and analyzed by pyrolysis Rock'n'roll-Eval of second generation, more precisely version 6.It acts, in the nomenclature, of the following samples:292, 293,294, 295, 296, 299, 302, 303, 1201, 1202, 1203,1204 and 1205.

The observation of the results of the laboratory seem to show that sample 299 would present a true anomaly which could have a serious impact on the values of the parameters to calculate in sight interpretation. The variations observed with the other samples of the same type of rock coming from same surround, are as striking as intriguing. That can be due to a natural contamination (mixtures of several sources) or artificial (not very sure handling at the laboratory).To avoid a skewed interpretation of the results, we straightforwardly put this sample at the variation (table 1$)$.

\begin{tabular}{|c|c|c|c|c|c|c|c|c|c|c|c|c|c|c|c|}
\hline Sample & $800 T$ & $\mathrm{SI}(\mathrm{mg} / \mathrm{g})$ & $52 / \mathrm{mg} / \mathrm{g})$ & $33(\mathrm{mg} / 9)$ & $\operatorname{Imax} t$ & Profoudes & $52 / 33$ & $\theta$ & $\mathbb{P}$ & $P G$ & $R_{0}$ & H & 10 & 18 & 19 \\
\hline 209 & 19.38 & 318 & 159.20 & 16190 & 477 & 654 & 0.58 & 1624 & $M$ & 162.38 & 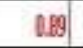 & 824.77 & 835.10 & 0.16 & 8.33 \\
\hline 32 & 1101 & 198 & 79.04 & 396 & 131 & 655 & 19.96 & 810 & 0.02 & 81.22 & 0.60 & 717.89 & 3597 & 1.18 & 7,35 \\
\hline 233 & $1: 23$ & 035 & 619 & 157 & 49 & 67 & 3.94 & 0.56 & 0.05 & 6.55 & 0.56 & 503.25 & 127.64 & 1.22 & 5.33 \\
\hline 302 & 1.24 & 008 & B.1. & 0.72 & 430 & 706 & 11.25 & 0.93 & 001 & 8.29 & 0.63 & 662.10 & 58.87 & 10.6 & 663 \\
\hline 1202 & 2.91 & 13:. & 31.69 & 08: & 400 & 735 & 39.85 & 332 & 0.04 & 33.20 & 0.58 & 1093.18 & 27.43 & 1.5 & 114. \\
\hline 2003 & 451 & 200 & 41.55 & 465 & 20 & $795:$ & $B .92$ & 4,36 & 0.05 & 49.56 & 0.55 & 921.29 & 118.33 & 0.15 & 965 \\
\hline 1201 & 878 & 256 & $\pi, 41$ & 268 & 633 & 795 & 27,02 & 7.50 & 0.03 & 74,99 & 0.63 & 82472 & 30.52 & 1.28 & 8.54 \\
\hline 1205 & 3.5 & 159 & $38: 12$ & 155: & 432 & 74 & 2459 & 397 & 0.04 & 39.71 & 0.62 & 965.16 & 3924 & 1.20 & 1005 \\
\hline 1204 & 467 & 233 & 48.79 & 218 & 485 & 748 & 1871 & 431 & 0.05 & 49.12 & Q.43 & 873.15 & 4668 & 2.50 & 923 \\
\hline 303 & 3.69 & 122 & 35.66 & 268 & 500 & 757 & 1356 & 3.65 & 0.03 & 35.90 & 0.53 & 916.71 & 67.61 & 1.32 & 9,45 \\
\hline 294 & 2.15 & 0.14 & 662 & Q9.9E: & 52 & 764 & 7.70 & 0.65 & 2003 & 6.86 & 062 & 631.48 & 61.92. & 2.23 & 6.53 \\
\hline 295 & 5.65 & 228 & 5461 & 122 & (35) & 791 & 1249 & 5.7 & 004 & 5719 & 0.71 & 935.52 & 205 & 1.39 & 97. \\
\hline 28 & 160 & 0.28 & 1431 & 095 & 486 & 825 & 1505 & 1.46 & 002 & 14.57 & 0.69 & 894,38 & 59.38 & 1.16 & 911. \\
\hline
\end{tabular}

Table 1: Analyze Rock'n'roll-Eval of the samples of Samba (Source:MRAC, 2012)

With regard to well DEKESE, it was sampled only in the interval of depth between $943 \mathrm{~m}$ and $1502 \mathrm{~m}$, primarily in the dark varvés shales, all of carboniferous age, the group of Lukuga (B.Linol, 2013).

The choice related to a sampling only in the dark varvés shales could be justified by the possibility that they were formed in an environment anoxic, in absence of oxygen, bioturbations, benthic fauna and digger organizations.

A total of 21 samples was taken and analyzed by pyrolysis Rock'n'roll-Eval of second generation, more precisely version 6.It acts, in the nomenclature, of the following samples:142, 145, 147, 148, 149, 150, 152, 155, 158, 160, 161, 162, 163, 164, 1225, 1227, $1233,1235,1236,1237$ and 1238 .

The observation of the results of the laboratory seem to show that sample 149 would present a true anomaly which could have a serious impact on the values of the parameters to calculate for interpretation. The variations observed with the other samples of the same type of rock coming from same surround, precisely for the value of Tmax generating a negative value of vitrinite, of it are a proof.To avoid a skewed interpretation of the results, we straightforwardly put this sample at the variation (table 2). 
International Journal of Advances in Scientific Research and Engineering (ijasre), Vol 5 (8), August-2019

\begin{tabular}{|c|c|c|c|c|c|c|c|c|c|c|c|c|c|c|c|c|c|c|c|}
\hline Ehestibe & fivis & Grop: & Litonge & 8000 & $31 \log (9)$ & $5 \mathrm{~kg} 9$ & $g(\log / g)$ & Iser? & Angoctes & 329 & 0 & 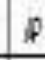 & PG & \& & $w$ & 10 & $B$ & 10. & $\lg e$ \\
\hline 142 & Deloge: & Wheg & Stalevarvinte: & 0.45 & 105 & 13 & $1 / 6$ & 42I] & 104 & 0.51 & I.14 & 01 & 13 & 1.4 & 35.73 & 7158 & 0.5 & 0.1 & Gatorits: \\
\hline 145 & Deloge & Why & Staevavinto: & 0.5. & 106 & 100 & 165 & 422 & $105 \mathrm{~S}$ & OAs & 101 & as & 1.11 & 1.4 & 11.7 & $12 n .5$ & 0.20 & a. & Catcorifet \\
\hline 147 & Delose: & whep & Stresonite & 24 & 10? & 2.4 & [B] & 43] & 108 & $3.1 \%$ & 136 & lar & 255 & 1.61 & 10333 & 33.5 & 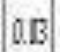 & $1 \mathrm{k}$ & Catcoifot \\
\hline 14 & Deles: & Lihg & Statemnite & $18 \mathrm{~J}$ & 105 & 158 & 192 & 445 & 100 & 0.7 & $10 ?$ & ar & $1 . \pi$ & 1.44 & 3552 & 5127 & $O . B$ & 0.3 & Cattorifst \\
\hline 144 & Denes: & When & Statevanire & 0.69 & IIS & 100 & J5I & 364 & $10 x$ & 019 & 101 & 03 & 111 & -1.6. & 12.7 & 7.37 & A.R & 0.21 & Caturibt: \\
\hline 151 & Deles: & Why & Styeugrisunte & $0 \pi$ & 10? & IA & 1.4] & $4: 1$ & $10 \%$ & D.fI & 103 & 0.2 & 13 & 1.4 & 3611 & $59 . n$ & a. 0 & 0,5 & Gatcoifot: \\
\hline 152 & Delose & Whag & 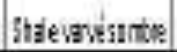 & 0.53 & 1103 & 110 & |B! & 413 & $94:$ & 012 & 191 & 02 & 113 & 1.35 & $8 B 7$ & 1547 & 0.5 & 0.5 & Gatorifot \\
\hline 155 & Deloge: & Why & Stbevavisnte & $23 \mathrm{I}$ & 108 & $2 n$ & 1.7 & 43] & 108 & 3.4 & 1.24 & OS & 235 & 1.61 & 38.7 & $3] .43$ & $O B$ & $1 M$ & Gatorits: \\
\hline 159 & Dolo: & Why & Stalervisntre & 0.54 & 105 & 1118 & 15I & 42I & 105 & 0.35 & 100 & 0.2 & I. & 1.4 & 813 & $x .13$ & 0.8 & $a x$ & Catcrift: \\
\hline 161 & Delose & When & Ittergvinnte: & 0.7 & 104 & 13 & M1f & 42] & $10 \%$ & 151 & 103 & 0. & 18 & 1.42 & $3: B$ & 2192 & 0.5 & 0.3 & Gatcorifs: \\
\hline (15] & Delos: & Lhig: & Stereavisnte & 0.57 & 106 & 13. & 167 & $4: 4$ & 113 & (14) & 109 & as & $1 x$ & 1.47 & 3199 & 69.07 & $a .5$ & 0.3 & Catorifist \\
\hline 162 & Delose: & Why & Stalevarinte & 0.45 & 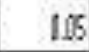 & 13 & 195 & 423 & 1137 & Q44 & 104 & as & 1.9 & 1,45 & 4001 & 10000 & 0.5 & 0.5 & Gatoritb: \\
\hline 16] & Delos: & Whyg & Stievarisante & $0.7 \pi$ & 107 & $1 x$ & $1.7]$ & 42.] & 1137 & 0.8 & III & 03 & 10 & 1.42 & 857 & 101.4 & (0.2.) & 0.3 & Gatorifs: \\
\hline 164 & Delose: & Whyg & 3tievasusnto: & 0.97 & ID? & 1.4. & $1 x$ & 42] & $112 x$ & 0.5. & 105 & 0. & 1.9 & 1.4 & 41.24 & 8:.4? & o.n & 0.4 & Gatorifet \\
\hline 1225 & Dekes: & Whes & Strlesavisnte & 0.42 & 104 & 119 & $I . M$ & 487 & 145 & 0.19 & 100 & 0.2 & 1.15 & 1.51 & 35.7 & 185.7 & $a n$ & 0.5 & Gatcrifst: \\
\hline 127 & Delos: & Lihg & Stitemite & 0.53 & 100 & lis & 12I & 415 & 150 & 0.3 & 10 & 0.5 & 13 & 1.2. & 4119 & $25 \%$ & $0.3:$ & 0.57 & Catorifst \\
\hline 1233 & Deles: & Whep & Stale:avinnte: & $0.5 f$ & 104 & 12 & I.A & 422 & 1190 & 0.4 & 103 & as & 1.5 & 1.4 & 175I & $85.7]$ & o.n & 0.5 & Catcrifts: \\
\hline 1235 & Deles: & Why & Sthevarisinte, & 0.45 & 104 & 119 & \pm .77 & 422 & 99 & 0.2 & 10 & 0.2 & 113 & 1.4 & 3151 & 15510 & 0.8 & 0.3 & Gatcrifot: \\
\hline $12 \mathrm{H}$ & Delo: & Whag & 5therarigg & a.5 & 108 & ix & 1.4I & 428 & 196 & 0.5 & 1. & 0.2 & 137 & 1.54 & $4: n$ & $645:$ & 0.18 & 0.0 & Gatcorifat \\
\hline 1237 & Delose & Why & It televvisunte & 0.9 & 109 & 1.8 & I11 & 487 & 100 & 0.4. & III: & 0.1 & 154 & 1.53 & i5.18 & $163:$ & $O B$ & 0.8 & Catoritse \\
\hline 123 & Delos: & Whe & Statevervintre & 0.55 & 104 & 17. & 155 & 42II & 1120 & Q4. & tows & gus. & 1.5 & 1.4. & 40.98 & 1000 & | Wir & {$[0,4]$} & Catcorifot \\
\hline
\end{tabular}

Table 2: Analyze Rock'n'roll-Eval of the samples of Dekese (Source:MRAC, 2012)

\subsection{Reinterpretation of geochemical data of well SAMBA and DEKESE}

3.2.1 Quality and quantity of the organic matter of the bed rocks of SAMBA

The rating scale of the potentialities of the rock-mothers is based on the percentage of Total Organic Carbon (COT) and certain data of pyrolysis Rock'n'roll-Eval, such as S1 and S2.

\subsubsection{Diagramme COT counters $\mathrm{S} 2$}

This diagram shows us the types of the kerogens present in the samples. 


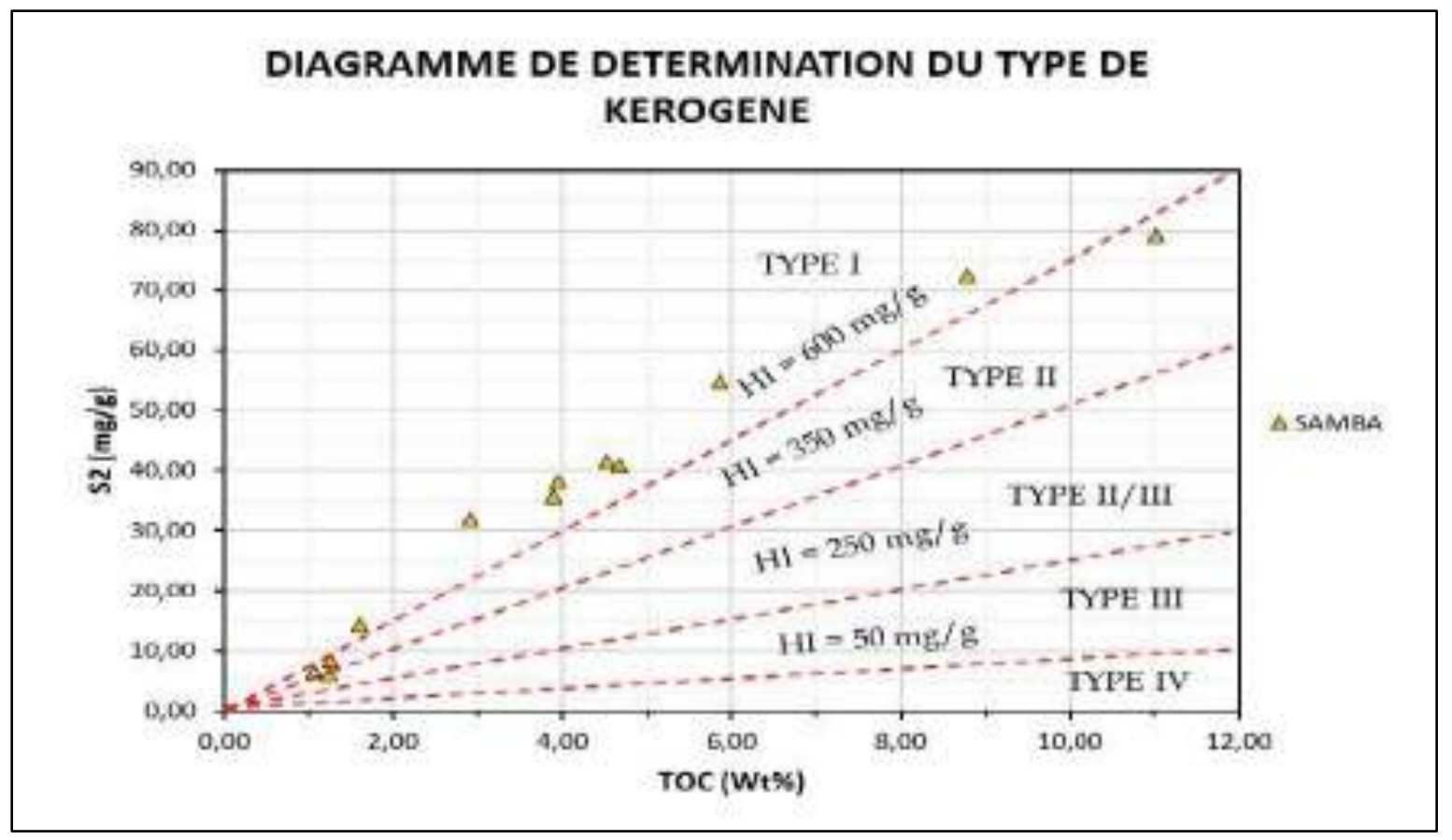

Figure 16: Diagram of discrimination on the origin of oils with Samba

Nearly $40 \%$ of the samples of rock-mothers of Samba show that produced oil or to produce would have migrated starting from other rock-mothers.

\subsubsection{The Tmax diagram counters IH}

This diagram enables us to specify the quality of the oil of the bed rock.

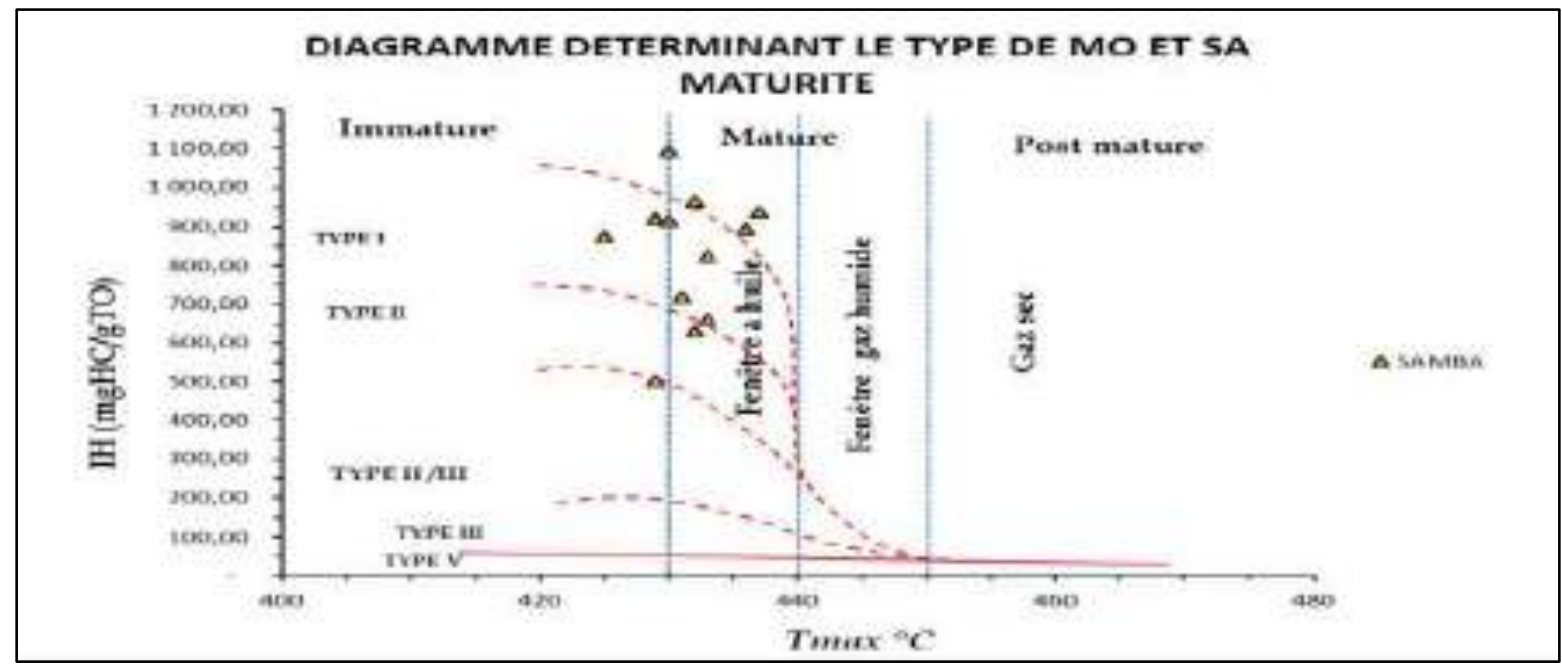

Figure 17: Diagram determining the organic type of matter and its maturity IH vs Tmax in Samba

This diagram informs that nearly $75 \%$ of samples taken in the well of Samba reached maturity and find themselves in the zone or fenestrates with oil.Nearly $25 \%$ fall into the immature zone and any in the gas zone, which confirms the possible absence of gases in this sector, by fault high maturity.This diagram also confirms that the kerogen of Samba is mainly of type 1, thanks to its hydrogen index which is particularly high, intrinsic character of the kerogens of the type 1 or lake type.

\subsubsection{The Tmax diagram counters IP}

This diagram gives us an illustration on the state of the maturity of hydrocarbons. 


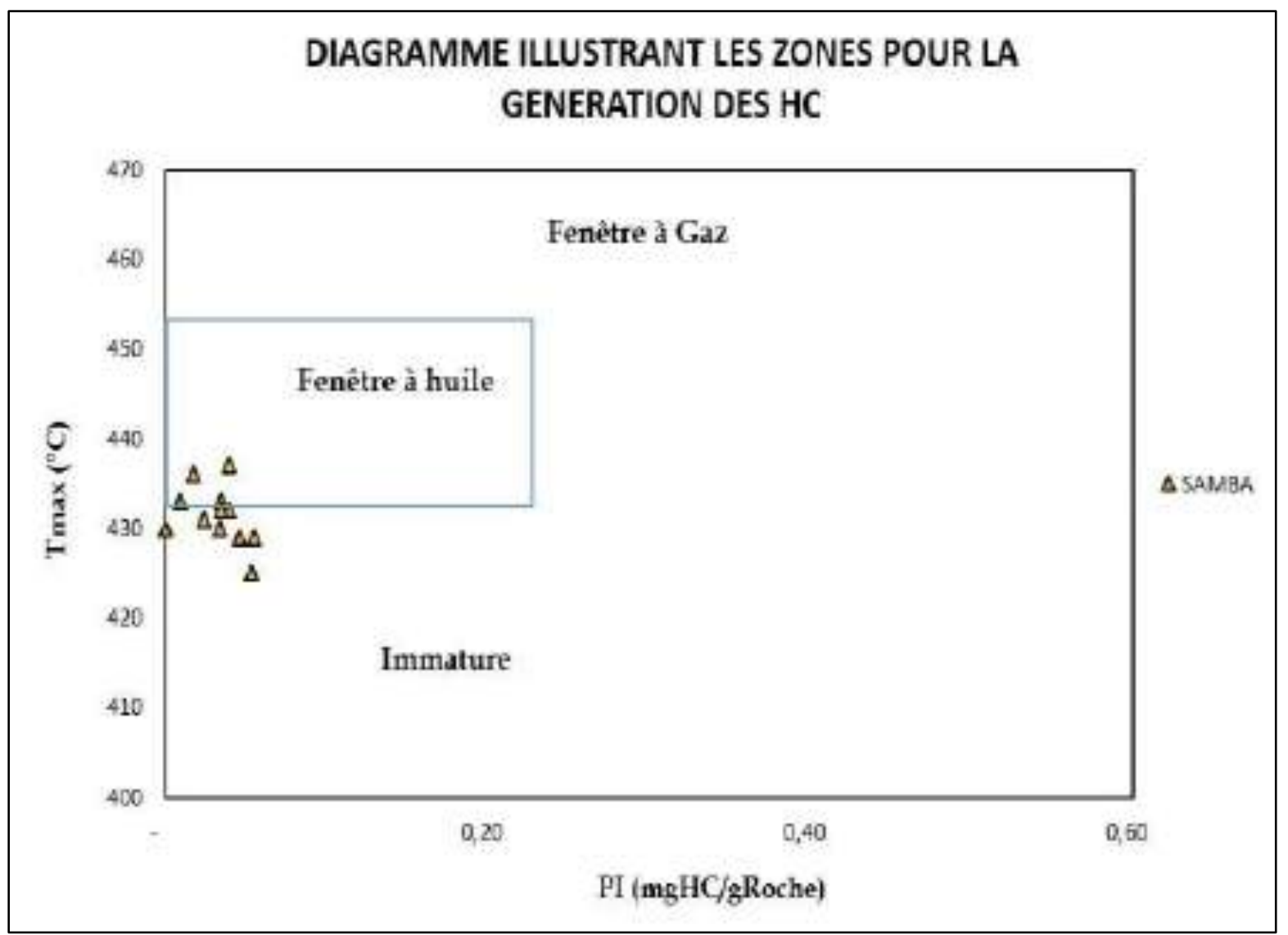

Figure 18: Diagram showing the index of productivity in connection with the maximum temperature with Samba

The definition of the window with oil is an also function of the type of kerogen (figure 28). For the "window with oil", Tmax varies in a small range of values for the kerogen of the type I, either between $432 \mathrm{C}$ and $455 \mathrm{C}$. Au-delà, it is or the immature zone or the zone with gas. These values indicate the conditions of "window to oil", but provided that IP is not higher than 0.4 .

The samples of Samba present very low values of varying index of productivity from 0.01 to 0.05 , but with a maximum fork of the temperatures making it possible part of these values to reach the window with oil.This diagram would bring probably more precision while showing than about half of samples reached necessary maturity to produce oil and then the others would be in the immature zone.This diagram still confirms that the organic matter of Samba did not reach maturity necessary to produce gas.

\subsubsection{The R0 diagram counters depth}

This diagram gives us a more precise information on the state of maturity of hydrocarbons, particularly of type 3 .

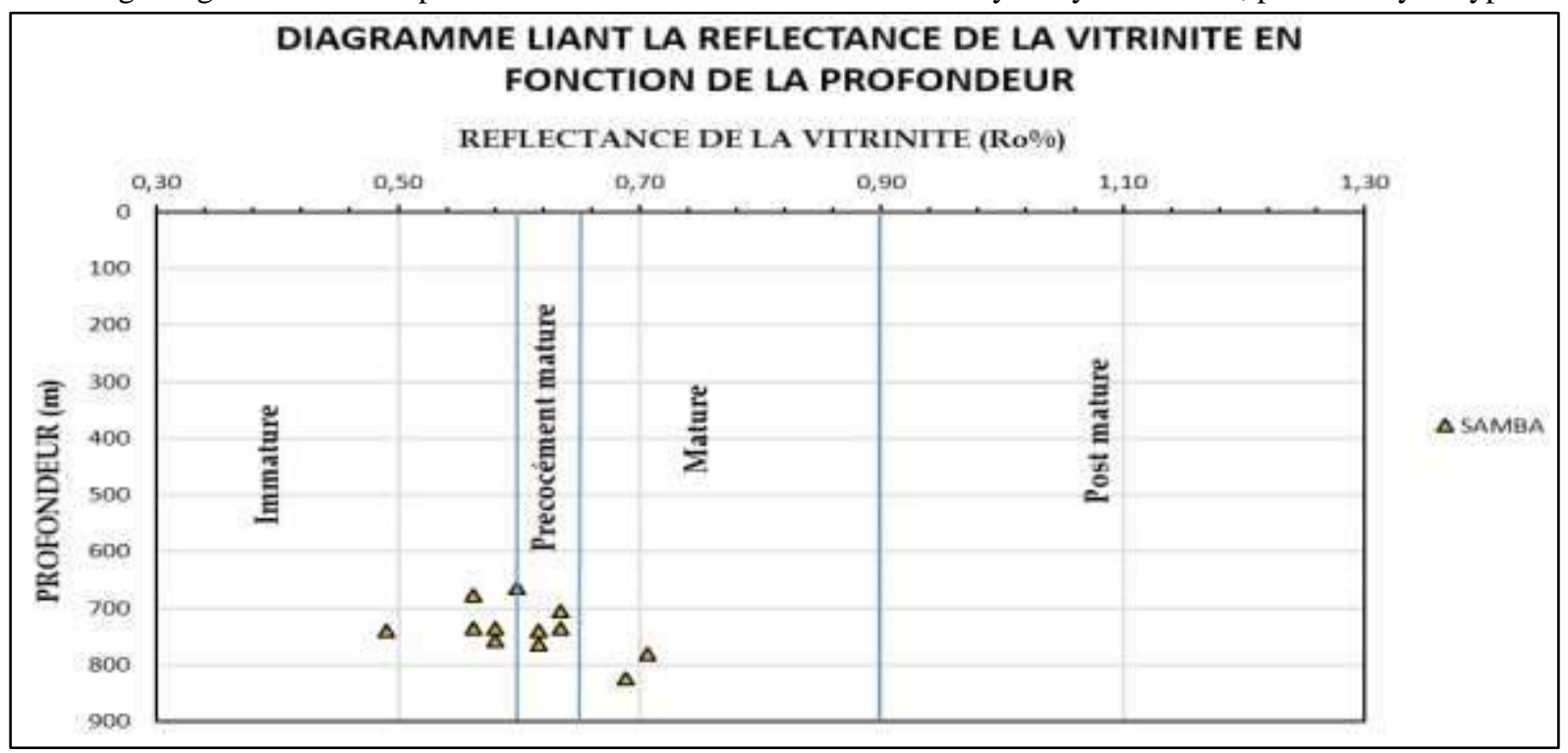

Figure 19: Diagram binding the reflectance of the vitrinite according to the depth to Samba 
The reflectance of the light of the organic matter increases with the depth and is quantified thanks to the vitrinite. The values of vitrinite ranging between 0.6 and $0.9 \%$, define the window in oil, which includes/understands the entirety of the precociously mature zone and the mature zone.

This diagram brings even more precision owing to the fact that it contains an intermediate zone between the immature and mature zone, called precociously mature zone.According to this diagram, $42 \%$ of the samples of Samba are found in the precociously mature zone, the mature zone takes $16 \%$ and the immature zone takes $42 \%$.

\subsubsection{The R0 diagram counters Tmax}

This diagram specifies us the good thermal evolution of the organic matter

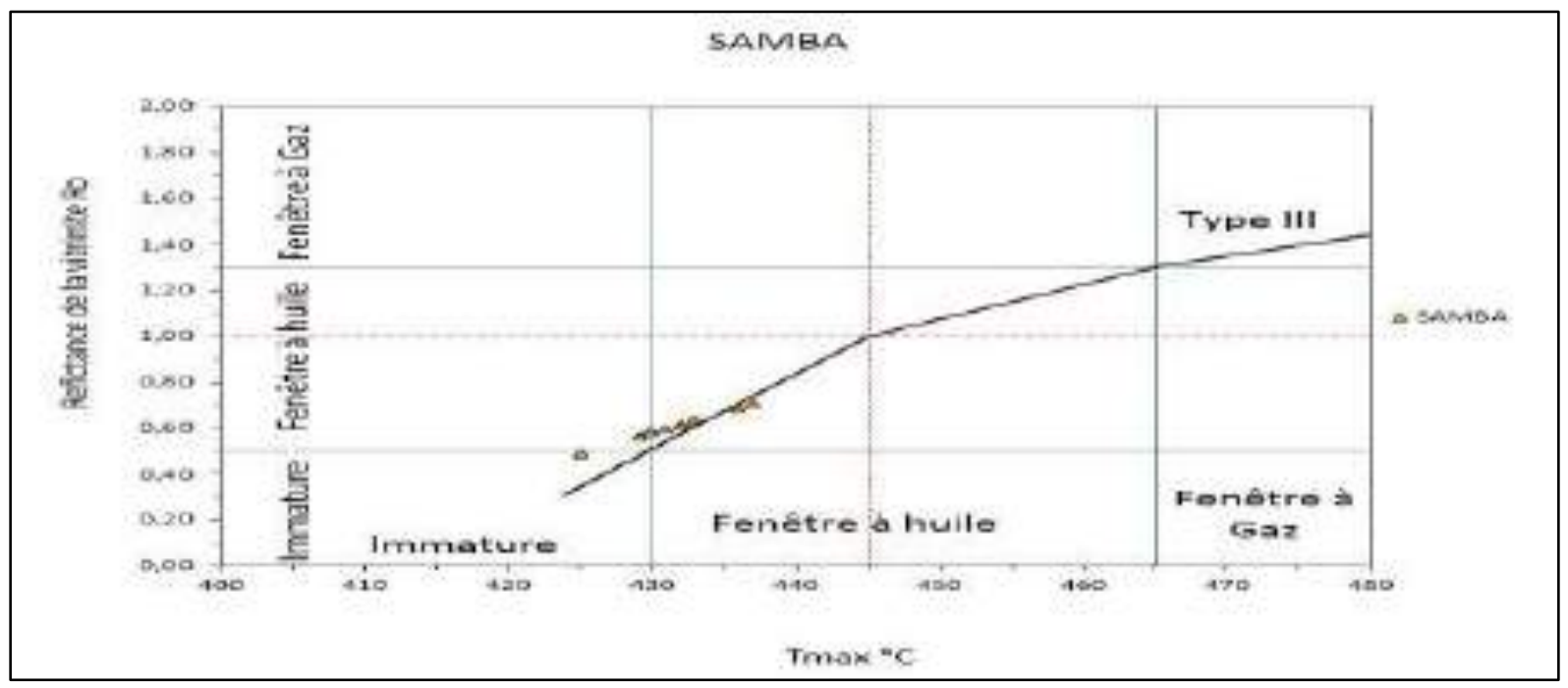

Figure 20: Diagram reflectance of the vitrinite against Tmax with Samba

Although this diagram is generally used for the kerogen of the type III, we used it in the case of the organic matter of the rocks of Samba to precisely confirm that this organic matter is not of type III.

\subsubsection{Diagram COT counters PG}

This diagram shows us in a precise way the evolution of the kerogen.

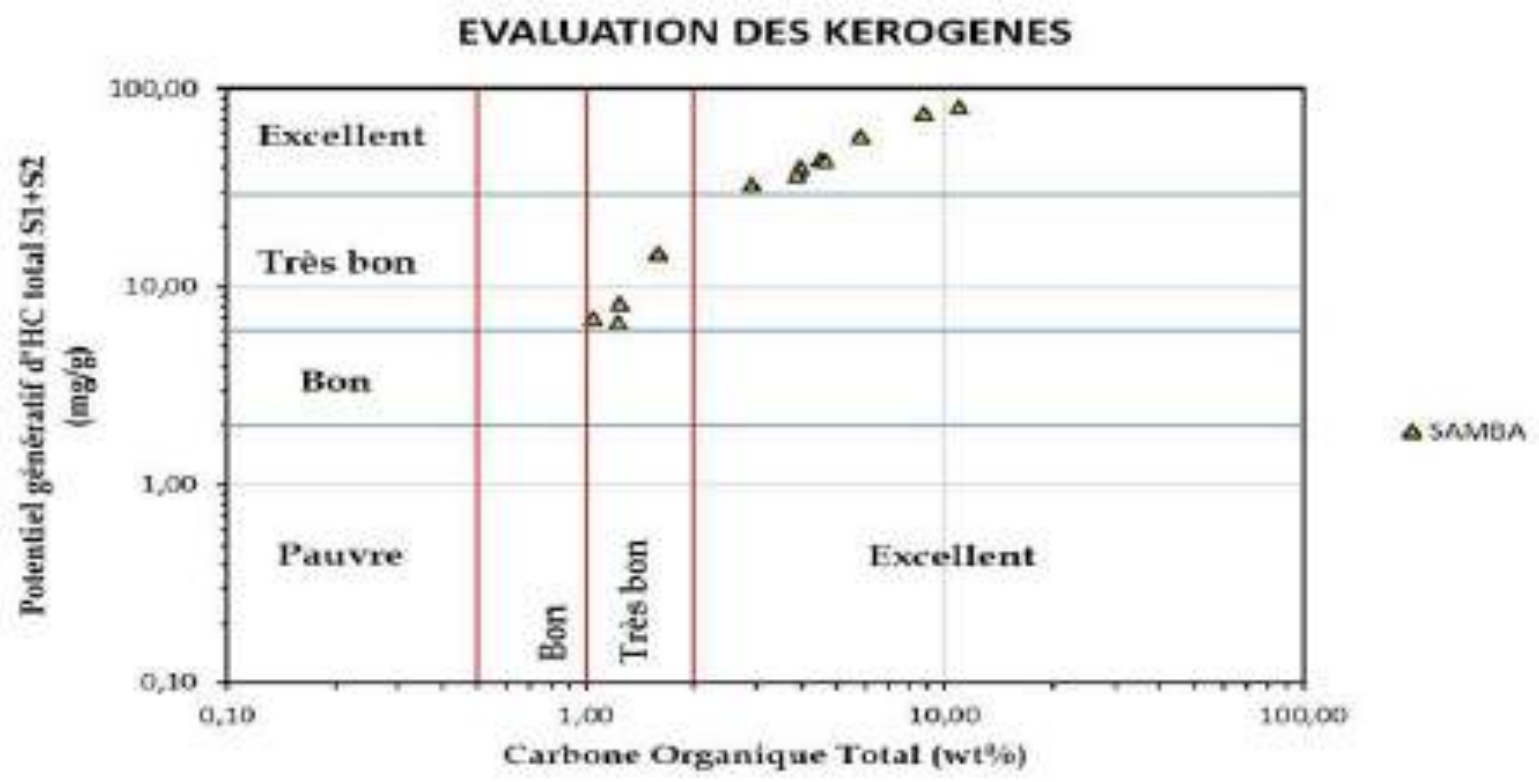

Figure 21: Diagramme COT counters PG for the evaluation of the kerogen with Samba

Diagram COT against PG, confirms indeed that in addition to its organic richness, the kerogen of Samba has a very good potential of generation. 


\subsubsection{Fork of expulsion of hydrocarbons}

The depth to which the rock source starts to expel hydrocarbons can be determined with stud S1/TOC against depth.Expulsion starts when the fork of report/ratio S1/TOC varies from $0.1-0.2$. In the case of Samba, one could thus locate the depth of expulsion between $665 \mathrm{~m}$ and $825 \mathrm{~m}$.

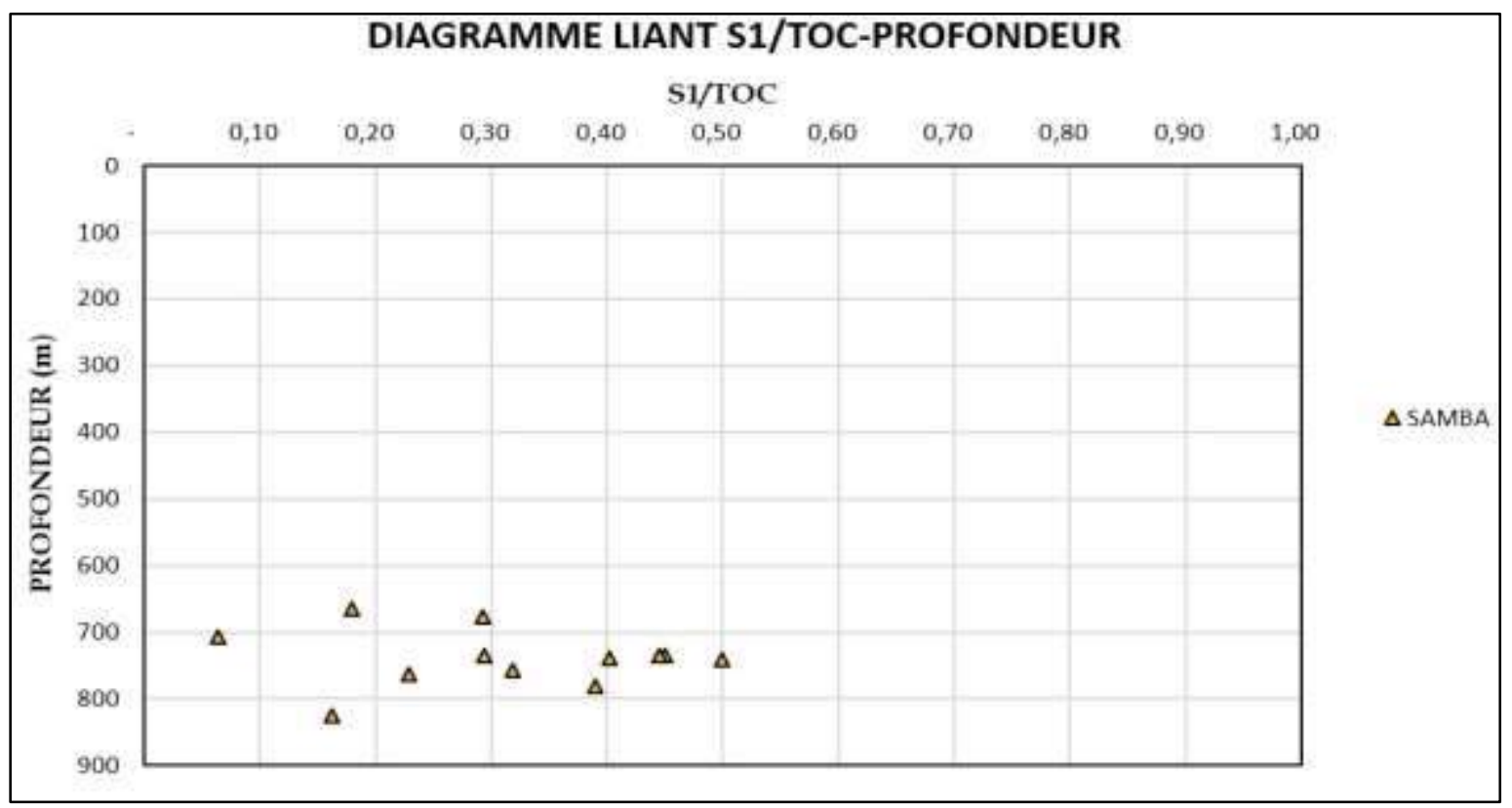

Figure 22: Diagramme binder S1/TOC and depth in Samba

3.2.2 Quality and quantity of the organic matter of the bed rocks of DEKESE

3.2.2.1 Diagram COT counters $\mathrm{S} 2$

\section{DIAGRAMME DE DETERMINATION DU TYPE DE KEROGENE}

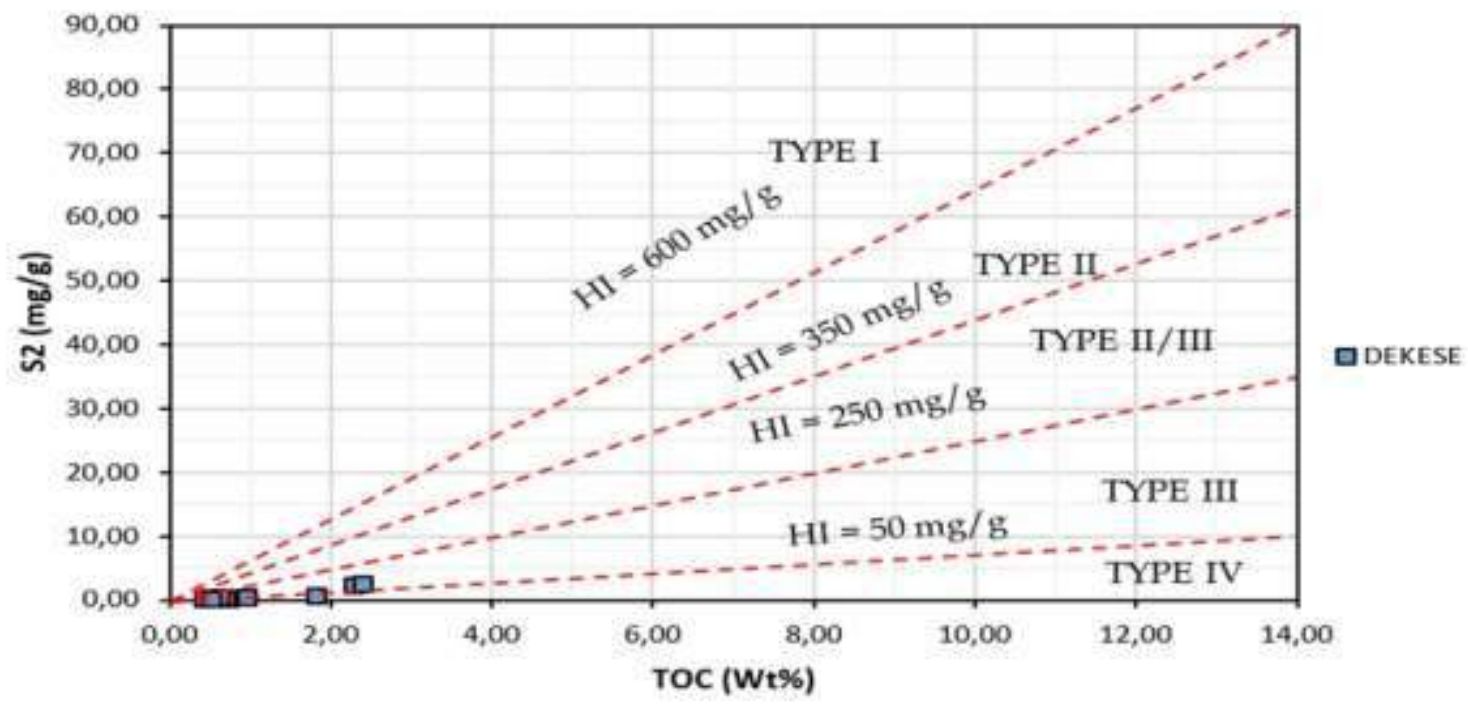

Figure 23: Diagram of determination of the type of kerogen with Dekese

For Dekese, contrary to Samba, all the samples show us that the organic matter contained in the bed rocks would be of type III and IV. This kerogen, of continental type is very low in hydrogen and very rich in oxygen.It made up into large parts of the higher plants is broken up into continental environment. This kerogen is of bad quality since it is rich in oxygen, which supports the formation mainly gases and of small quantity of oil. 


\subsubsection{Diagram COT counters S1}

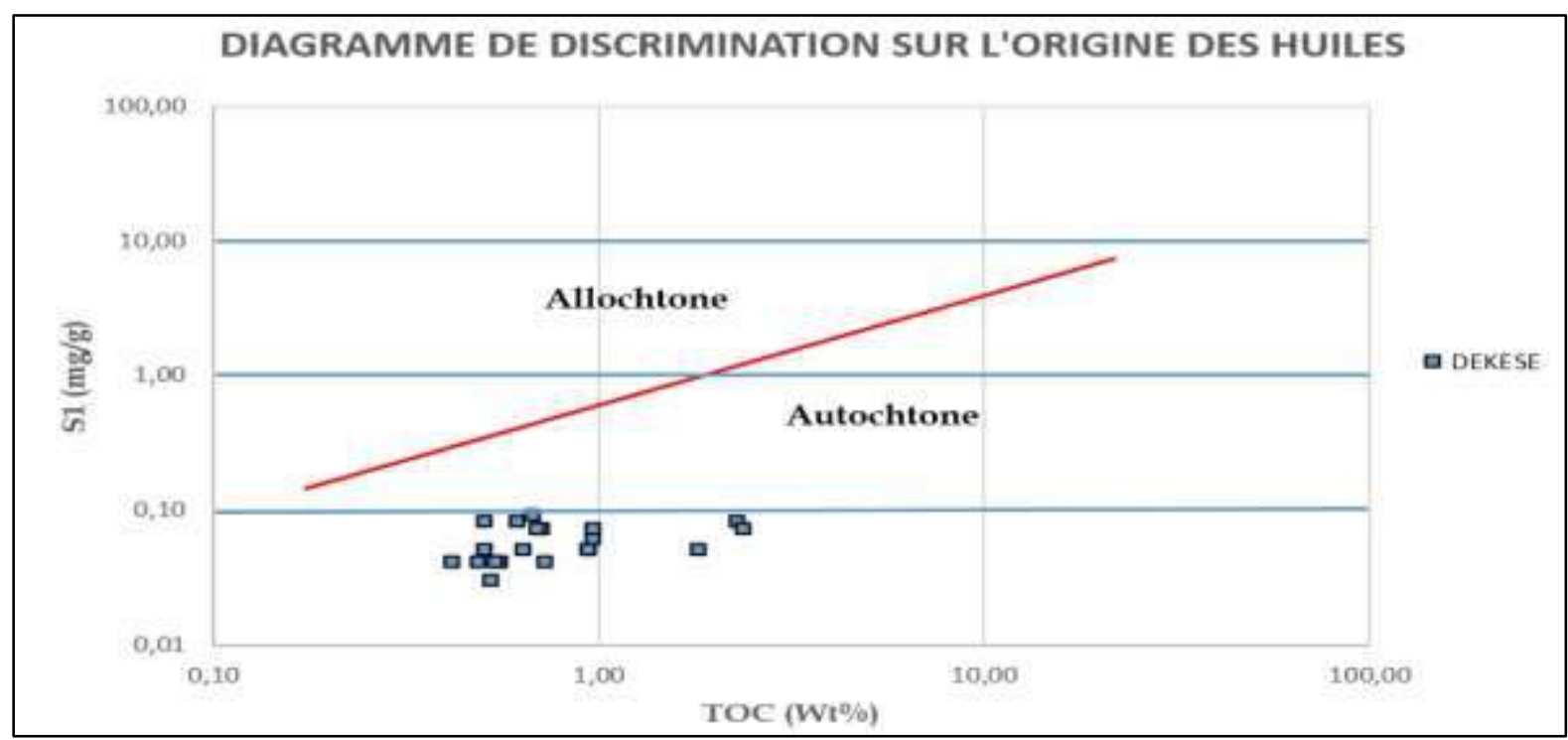

Figure 24: Diagram of discrimination on the origin of oils COT against S1 with Dekese

The whole of the samples of rock-mothers of Dekese show us that oils produced to produce do not seem to have migrated of other rock-mothers. They would have been formed on the spot in the bed rock.

\subsubsection{Diagram COT counters IH}

\section{EVALUATION DES KEROGENES}

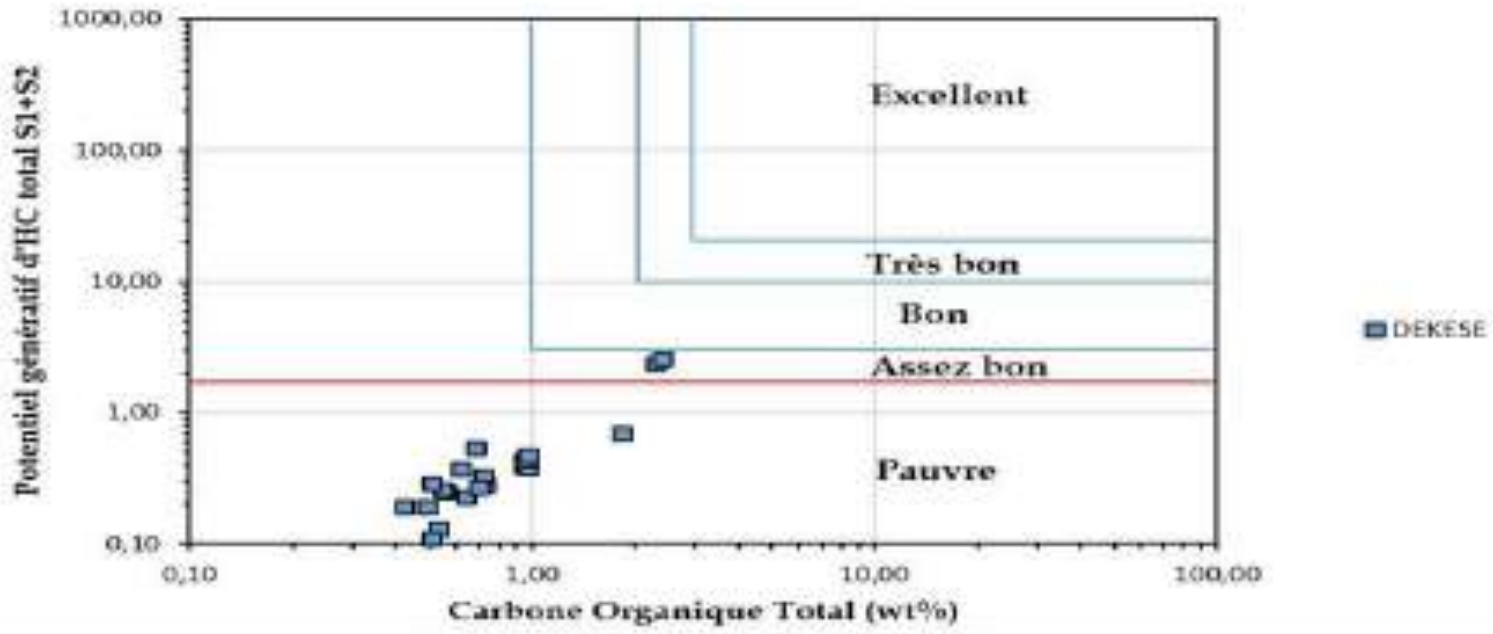

Figure 25: Diagram of evaluation of the kerogens with Dekese

As we said in the first diagram of Dekese, only $10 \%$ of the samples of the bed rock can produce oils, and the $90 \%$ others of samples show us that they will be able to produce only gas or then nothing the whole, i.e. kerogen sleeping or died.With a sufficient maturity, one could thus have a diphasic layer but with a great quantity of gas.

\subsubsection{The Tmax diagram counters IH}




\section{DIAGRAMME DETERMINANT LE TYPE DE MO ET SA}

MATURITE

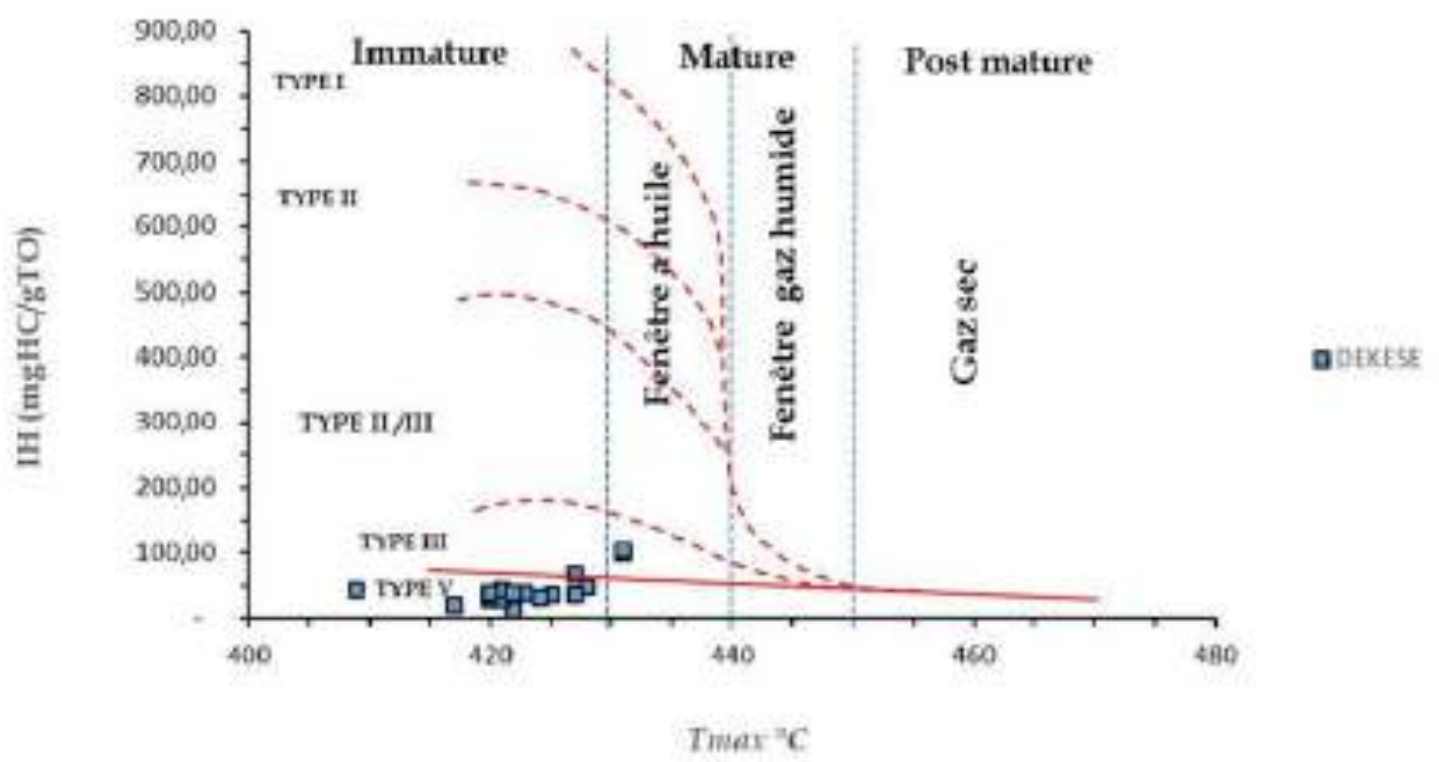

Figure 26: Diagram determining the organic type of matter and its Tmax maturity against IH with Dekese

This diagram assure us that just $10 \%$ of the samples of the rock-mother could reach a level of maturity and find themselves in the window with oil.While the others $90 \%$ of the samples of the bed rock are immature and of type IV (in majority) which represent dead hydrocarbons.

3.2.2.5 The Tmax diagram counters IP

DIAGRAMME ILLUSTRANT LES ZONES POUR LA GENERATION DES

$\mathrm{HC}$

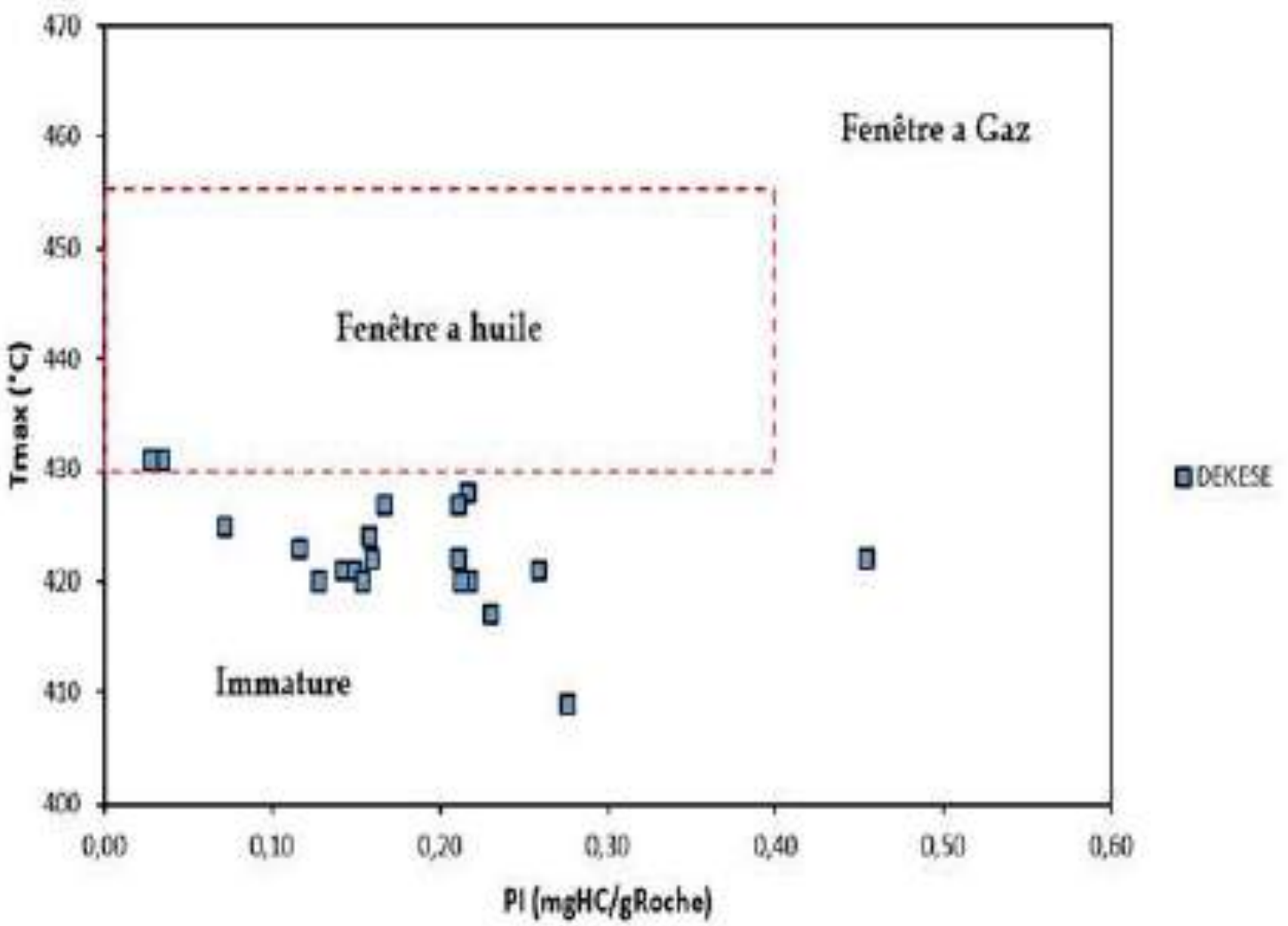

Figure 27: Diagram illustrating the zones for the generation of the Tmax hydrocarbons against IP with Dekese 
The samples of Dekese, present low values of index of productivity which vary from 0.03 to 0.28 and of the low values of the maximum temperature which exclude them from the window with oil. This diagram gives us more precision on the fact that $90 \%$ or the totality of the samples did not reach an adequate maturity to produce oils. This diagram comes in support to our interpretation, which confirms that the organic matter of Dekese contained in the bed rock can only produce very small quantities of oil.

\subsubsection{The R0 diagram counters depth}

The reflectance of the light of the organic matter increases with the depth and is quantified thanks to the vitrinite.The values of vitrinite ranging between 0.6 and $0.9 \%$, define the window in oil, which includes/understands the entirety of the precociously mature zone and the mature zone.

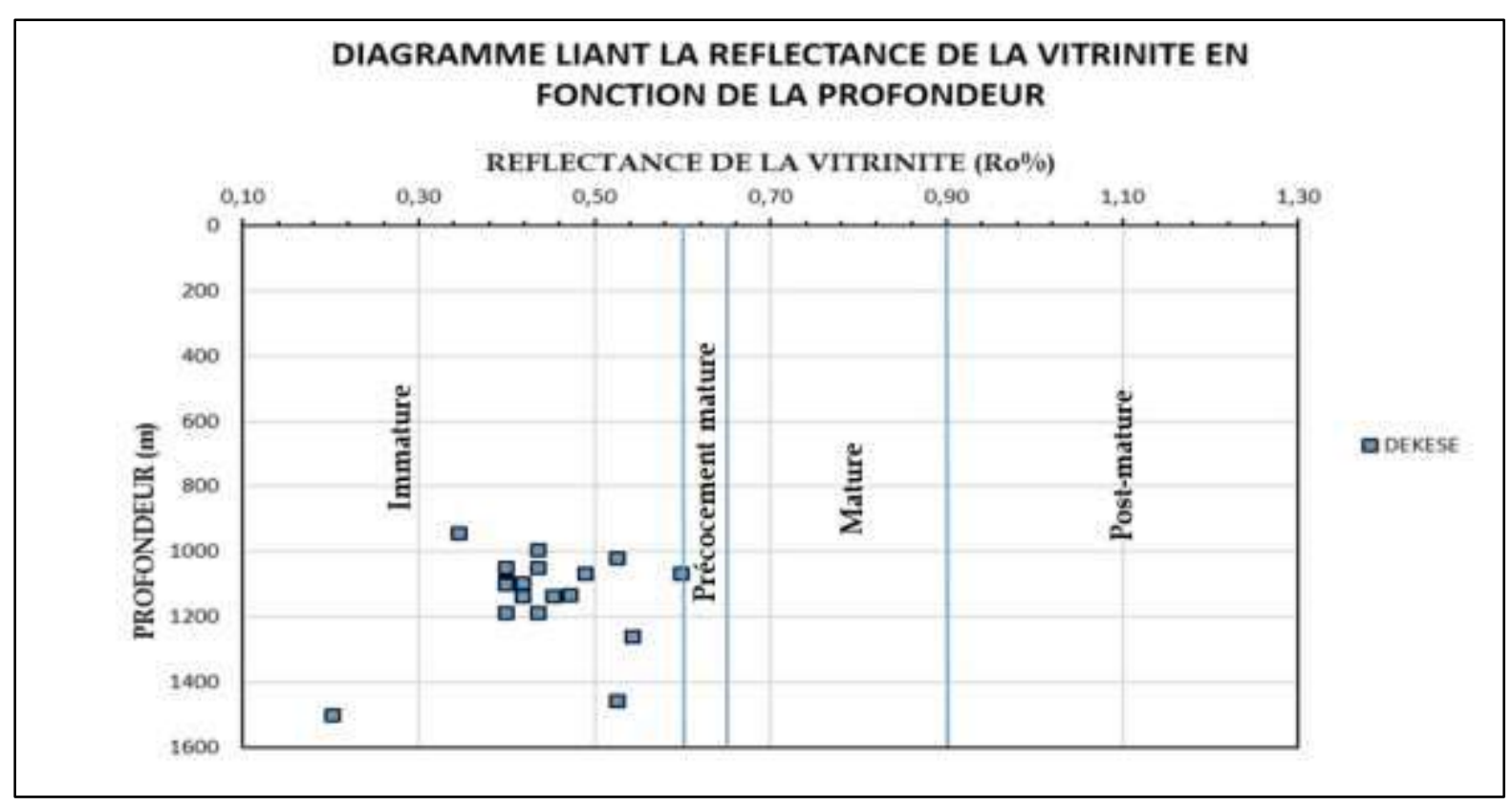

Figure 28: Diagram binding the reflectance of the vitrinite according to the depth to Dekese

This diagram brings even more precision owing to the fact that it contains an intermediate zone between the immature and mature zone, called precociously mature zone.According to this diagram, we have just two samples which are in the precociously mature zone, the remainder being in the immature zone.

\subsubsection{The R0 diagram counters Tmax}

\section{DEKESE}

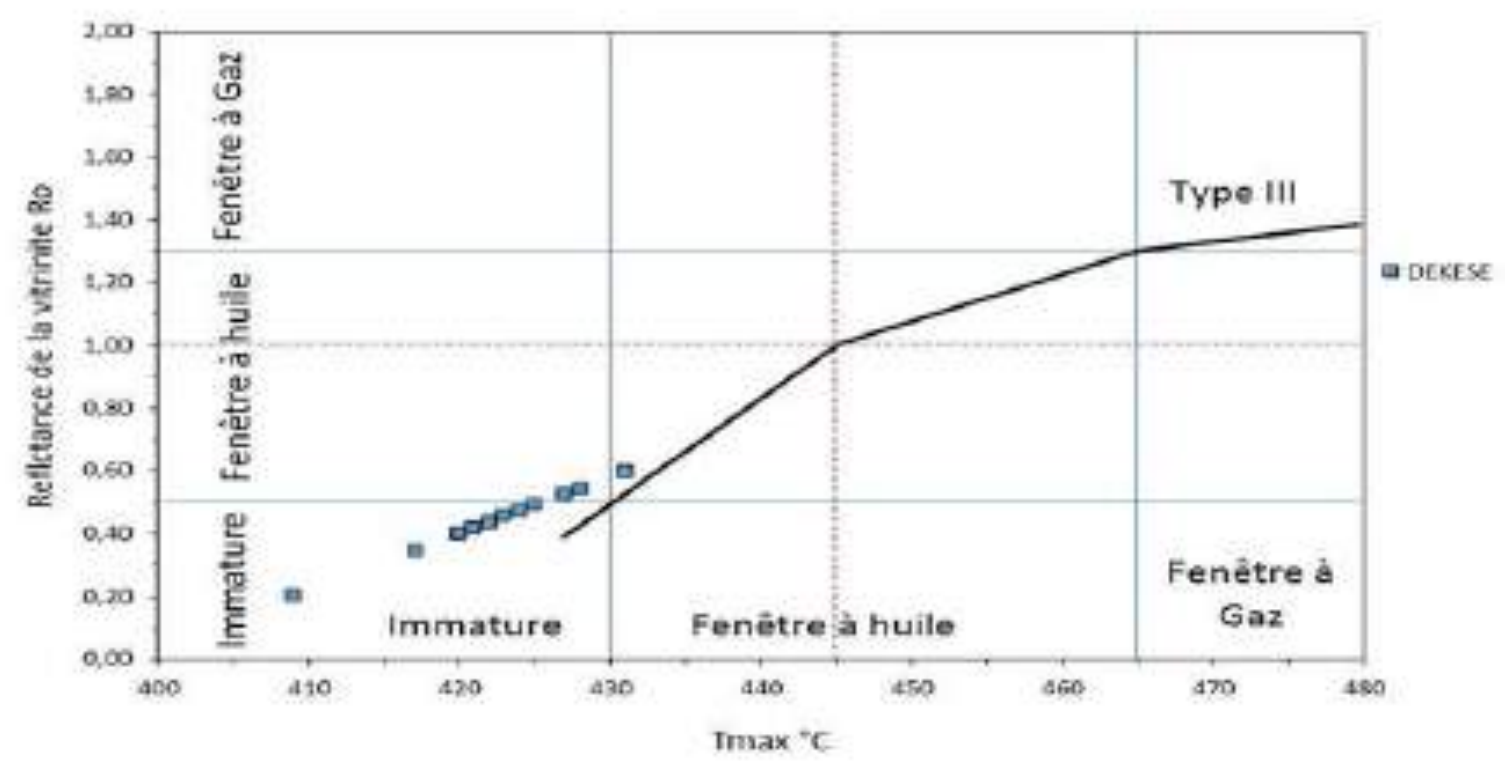


Figure 29: Diagram reflectance of the vitrinite against Tmax with Dekese.

This diagram makes it possible to reinforce the conviction that Tmax and the reflectance of the vitrinite can all be used for the evaluation of the maturity of an organic matter, starting from the linearity of the common points, but also for the case of the samples of Dekese to confirm the membership of the majority at the immature zone (90\%) and their parallelism limited with the curve of the type III, indicating the membership very partial to this type of kerogen, since it belongs more to type IV.

\subsubsection{Diagram COT counters PG}

Diagram COT against PG, confirms indeed that the kerogen of Dekese has a poor potential of generation at good.It shows, however that the richness of the organic matter is poor with excellent.

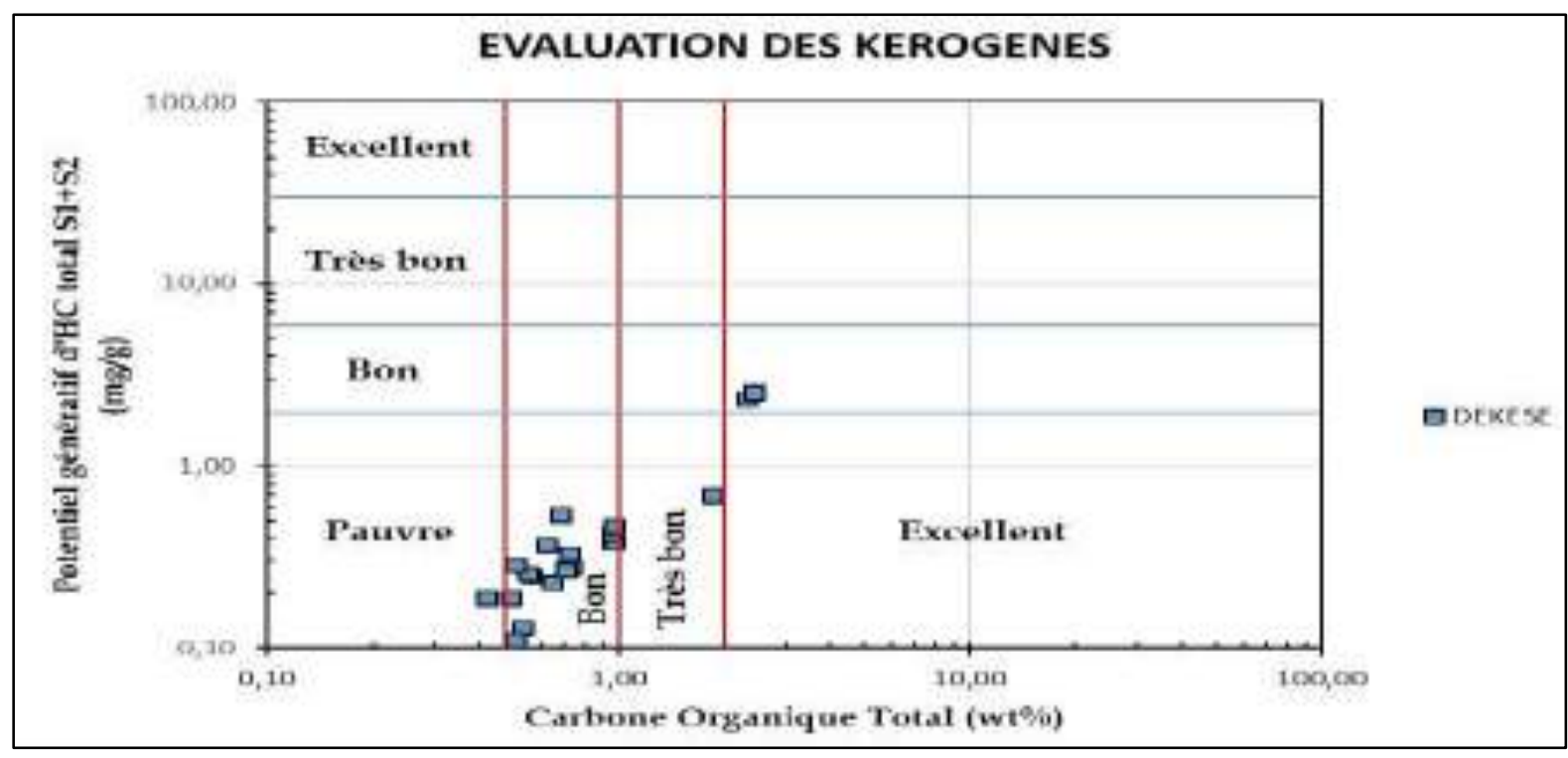

Figure 30: Diagramme COT counters PG with Dekese

\subsubsection{Fork of expulsion of hydrocarbons}

The depth to which the rock source starts to expel hydrocarbons can be determined with stud S1/TOC against depth.Expulsion starts when the fork of report/ratio S1/TOC varies from $0.1-0.2$ In the case of Dekese, one could thus locate the depth of expulsion between $1020 \mathrm{~m}$ at $1502 \mathrm{~m}$, provided that there are formed hydrocarbons.

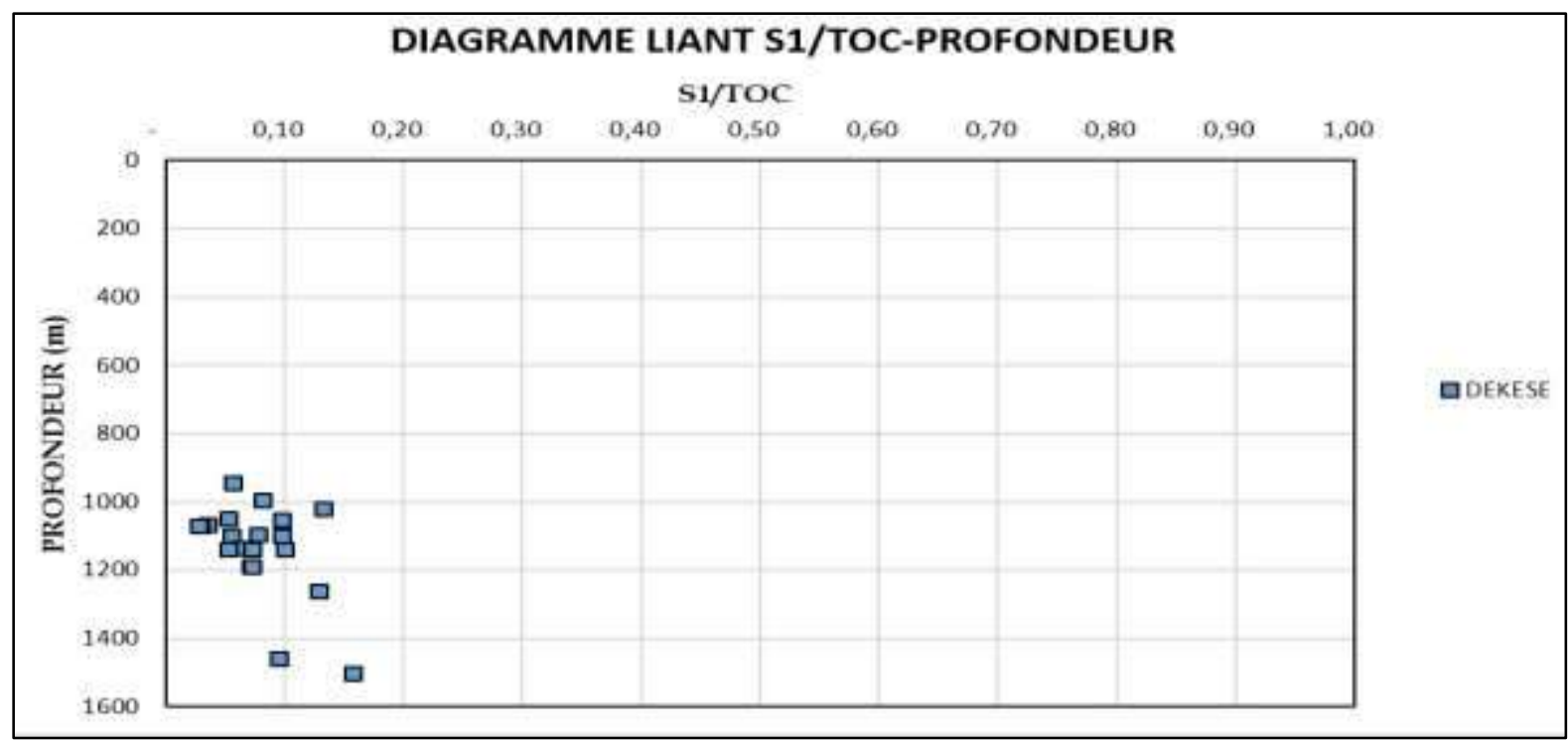

Figure 31: Diagram binding S1/COT with the depth to Dekese

\subsection{The coefficient of correlation of Pearson}

The coefficient of correlation of Pearson is a statistical measurement of the force of the linear relation between the pairs or couples of data. The coefficient of correlation varies between -1 and +1 , with -1 indicating a perfect negative correlation, +1 
indicating a perfect positive correlation and the 0 absence of correlation.A variable correlated with itself, will always have a coefficient of correlation of +1 .

\subsubsection{For the well of samba}

The data processing of well of Samba by the software Oasis Montaj indicates a certain number of correlations between parameters of pyrolysis Rock'n'roll-Eval (figure 44).We will consider only certain significant correlations.

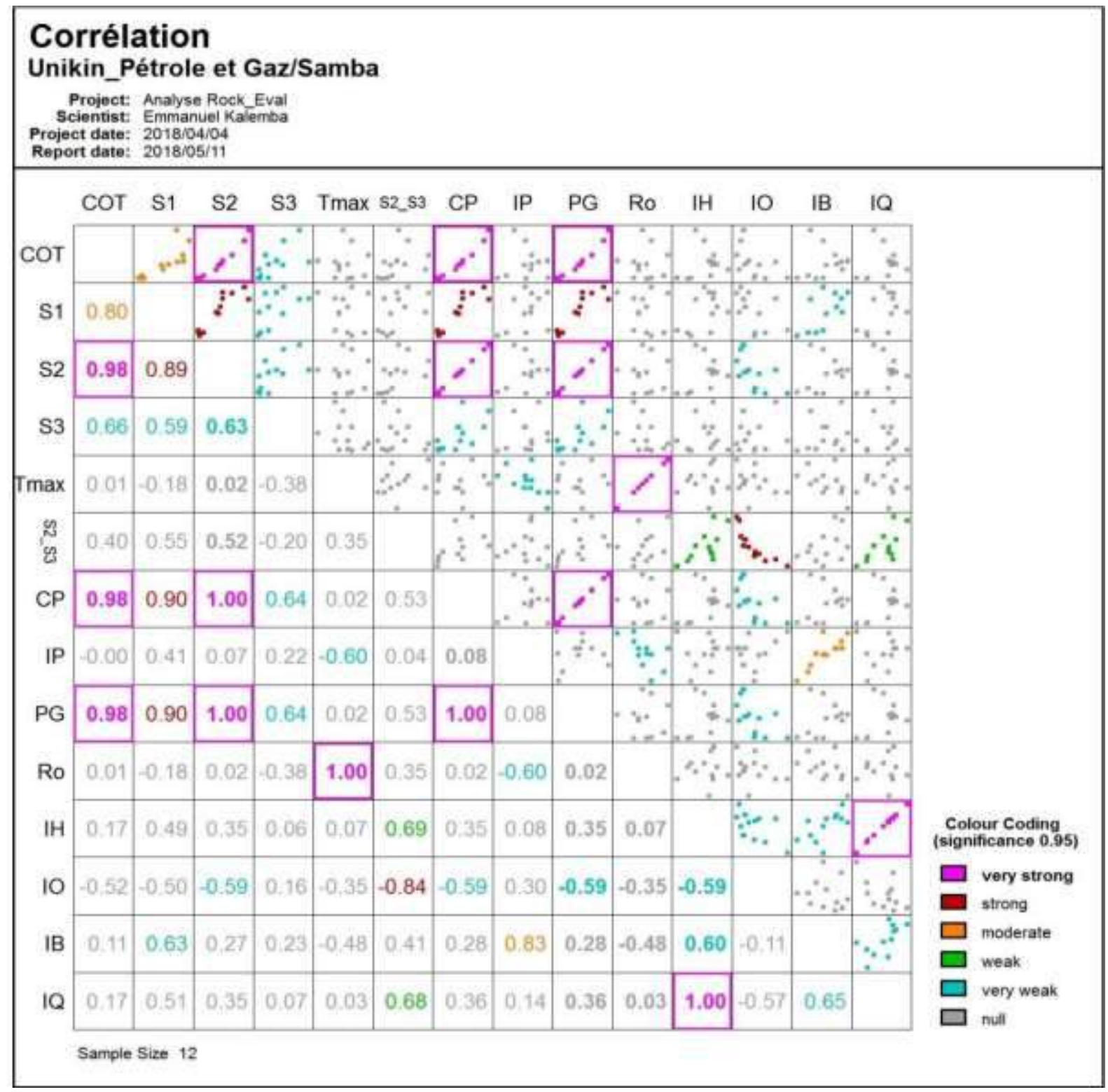

Figure 32: Correlation of Pearson per Montaj Oasis for Samba

- $\quad$ a positive correlation between COT, S2, CP and PG, indicating the contribution of the richness of the organic matter on the genetic potential of the rock, the quantity of carbon pyrolysable and the potential of the rock to produce hydrocarbons after maturation;

- a correlation moderated between COT and S1 because the found free hydrocarbons are only partially related to the organic richness of the rock-mother of Samba;

- a null correlation between COT and IH, thus between COT and IO, indicating the independence of IH and IO compared to COT;

- a weak correlation between COT and Tmax indicating that the maturity of the rock is independent of the richness of the organic matter;

- a perfect positive correlation between S2 and CP and PG, indicating that the genetic potential and organic carbon pyrolysable are directly related to hydrocarbons generated after cracking;

- a null correlation between Tmax-IH and R0 - IH, indicating that the quality and the quantity of the hydrocarbons pyrolysables are dependent only on certain maturities and necessarily related to the stages of immaturity and over maturity; 
- A negative correlation between IH and IO confirms that the increase the quality and the quantity of the hydrocarbons pyrolysables contrast with that of the oxygen contents in the rock;

- A positive correlation between S2 and R0, indicating that the potential of the rock to produce hydrocarbons increases with the level growing of maturity;

- Tmax and R0 are found positively correlated, confirming that the two parameters can be used as indicators thermics of maturity.

These same parameters, compounds with others, were analyzed in order to establish coupled correlations of Pearson (figure 33).

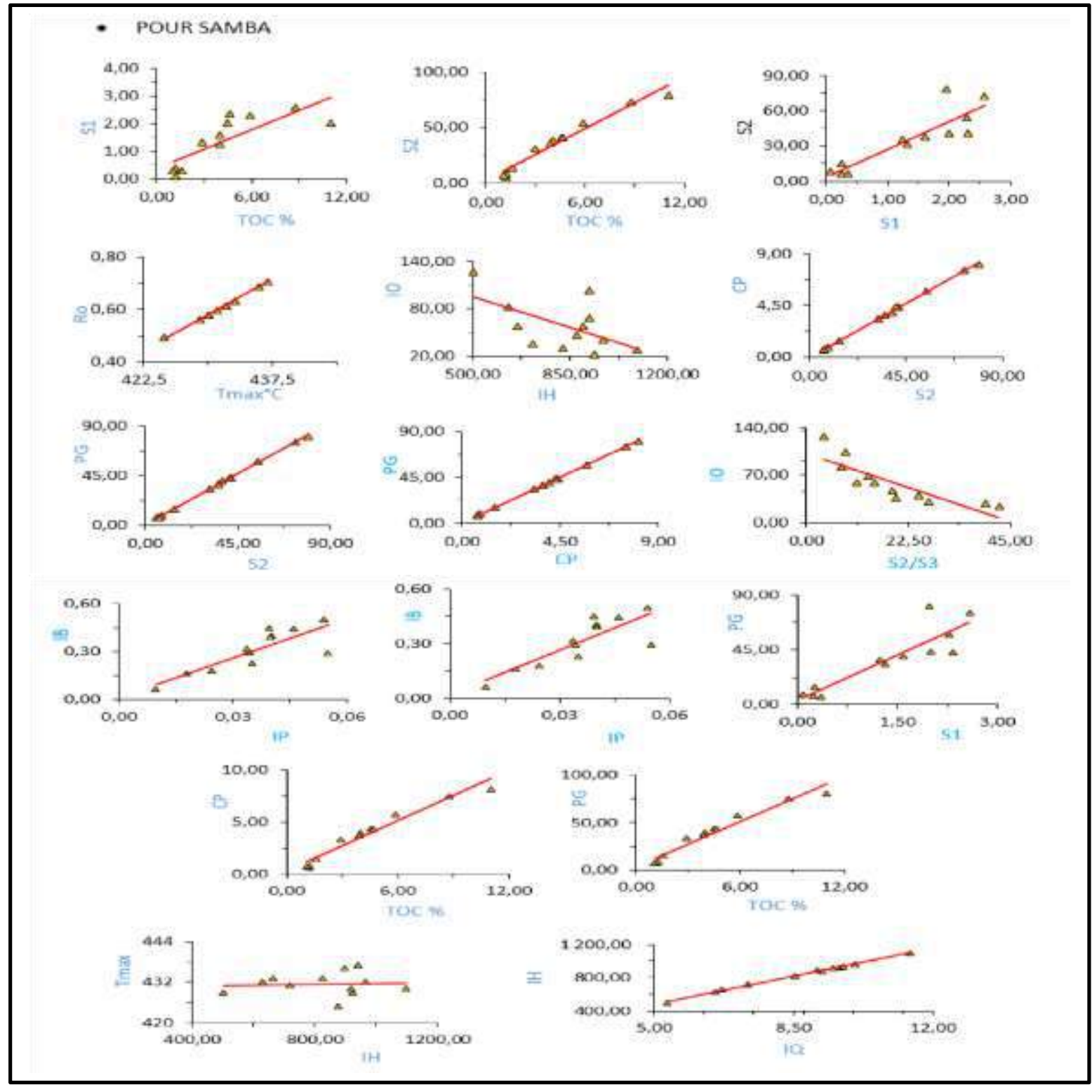

Figure 33: Correlation of Pearson for certain parameter by Excel 2016 to Samba

In the idea to always reinforce the assertions on the correlations between parameters, a stratigraphic log with lithology and the various parameters of pyrolysis Rock'n'roll-Eval support the conclusions found higher (figure 34). 
International Journal of Advances in Scientific Research and Engineering (ijasre), Vol 5 (8), August-2019

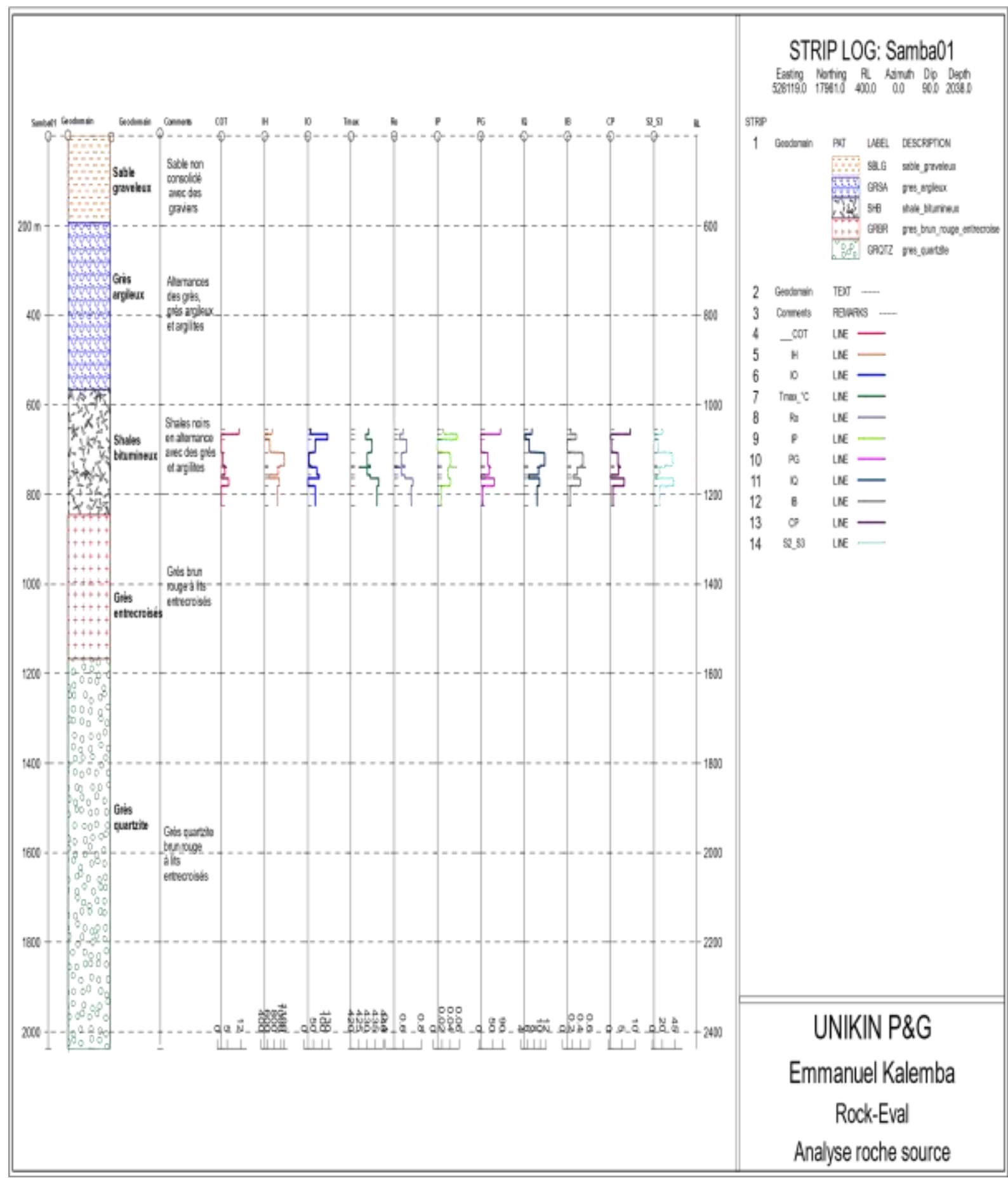

Figure 34: A stratigraphic log with the lithology and the various parameters of pyrolysis Rock'n'roll-Eval to Samba

\subsubsection{For the well of Dekese}

As for the well of Samba, the well of Dekese by the software Oasis Montaj indicates a certain number of correlations between parameters of pyrolysis Rock'n'roll-Eval (figure 35).

We will consider only certain significant correlations. 


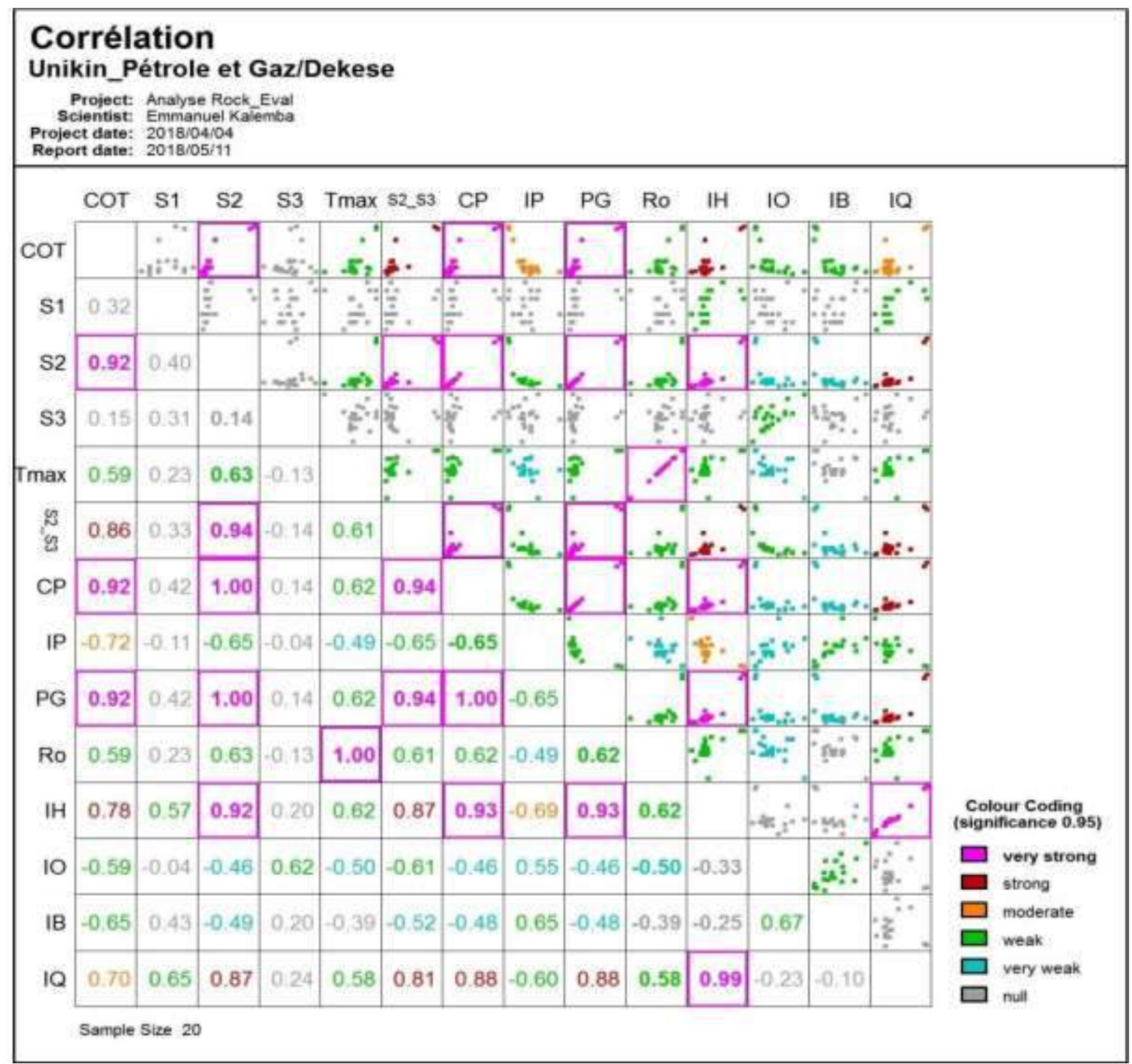

Figure 35: Correlation of Pearson per Oasis Montaj de Dekese

- Positive +1 correlation between COT, S2, CP and PG, indicating the contribution of the richness of the organic matter on the genetic potential of the rock, the quantity of carbon pyrolysable and the potential of the rock to produce hydrocarbons after maturation;

- A slightly positive correlation between COT and S1, indicates that the found free hydrocarbons are only partially related to the organic richness of the rock-mother of Dekese;

- A positive correlation between COT and $\mathrm{IH}$, indicates to us that the quality and the quantity of the organic matter are related to organic carbon total;

- On the other hand a negative correlation between COT and IO, indicating the independence of IO to organic carbon total;

- A positive correlation between COT and Tmax indicating that the thermal maturity of the rock is dependent on the richness of the organic matter;

- A perfect positive correlation between S2 and CP and PG, indicating that the genetic potential and organic carbon pyrolysable are directly related to hydrocarbons generated after cracking;

- A weak positive correlation between Tmax-IH and R0 - IH, indicating that the quality and the quantity of the organic matter are slightly related to the thermal stage of maturity of oils present in the bed rock;

- A negative correlation between IH and IO confirms that the increase the quality and the quantity of the organic matter contrasts with that of the oxygen contents in the rock;

- A slightly positive correlation between S2 and R0, indicating that the potential of the rock to produce hydrocarbons increases with the level growing of maturity in the rock;

- Tmax and R0 are found perfectly correlated, confirming that the two parameters can be used as indicators thermics of maturity. 
These same parameters, compounds with others, were analyzed in order to establish coupled correlations of Pearson (figure 36).

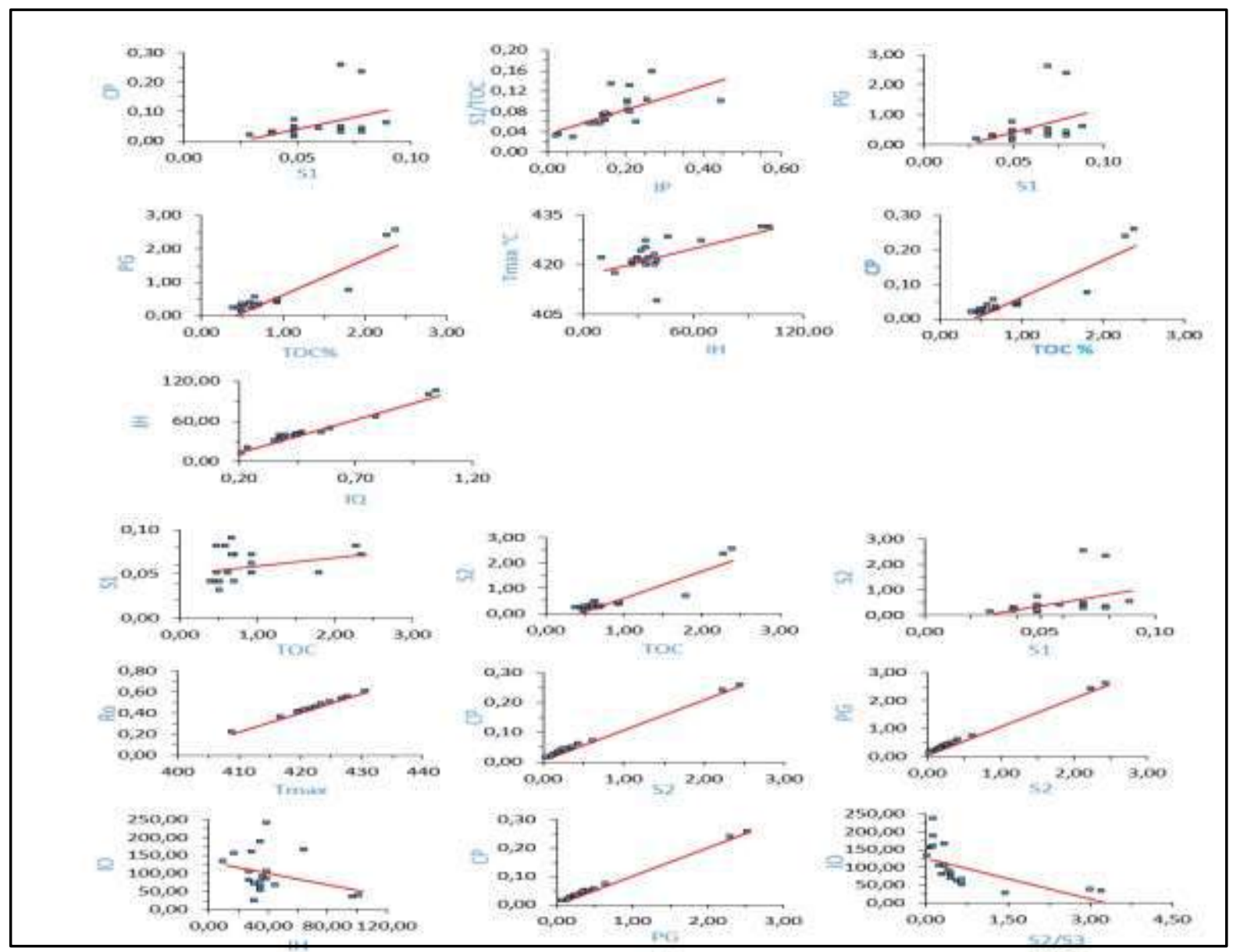

Figure 36: Correlation of Pearson of certain parameter by Excel 2016 for Dekese

\section{GENERAL CONCLUSION AND OUTLINES}

The analysis and the interpretation of the results of the technique of Pyrolysis Rock'n'roll-Eval of the samples of the wells of Samba and Dekese (central Basin of the RD Congo) make it possible to draw the conclusions which follow. However,

- the analysis of the geochemical data of Samba and Dekese released from the differences essential according to the parameters studied using the various diagrams in pyrolysis Rock'n'roll-Eval:

* With Samba, the parameters show values of COT à.70\% meaning of the rocks of very good quality to excellent.Other parameters of Samba show that the organic matter contained within the bed rock is an organic matter of type 1 (lake) mature, rich in hydrogen what confers a quality to him is a quantity of significant oil.Most of these oils are autochtones and reached the window of expulsion for the migration.

* In Dekese, the parameters on the other hand show values of COT with $86 \%$ like the poor with rather good.Other parameters of Dekese show that the organic matter is dominated by type 4 (dead hydrocarbon), but to see $10 \%$ very little are found in type 3, all of continental type, low in hydrogen index what gives us poor hydrocarbons mainly. Only $10 \%$ of the samples reached the window of maturity, assure us that the organic matter has a low potential of generation of the hydrocarbons (10 to $30 \%)$.

By what precedes, it proves that, from an oil point of view, Samba presents better prospects for thorough exploration compared with Dekese.Samba, which is located in block 4 of the central Basin, thus starts again through our work all the oil interest of this block, which in our opinion, should profit from substantial work of geophysics with tightened mesh, in particular gravimetry, magnetometry, magnetotelluric and seismic reflexion, in sight the reprogramming of the wells of drilling while having made best possible interpretations.

Thus, by this work we believe to have contributed our share to the scientific study of exploration and oil production of the Basin of the central Basin (RD Congo).

\section{Acknowledgement}

We thank all those which contributed to the realization of this modest work. 


\section{BIBLIOGRAPHY}

1. Béhar, F, Beaumont, V, Of B Penteado, H.L.(2001) Rock'n'roll-Eval 6 Technology:Performances and Developments. Oil \& Gas Science and Technology - Rev.IFP, 56, 111-134.

2. Buiter SJH, Stenberger B, Medvedev S, Tereault JL (2012) Could the mantle caused cuts subsidence of the Congo Basin?Tectonophysics 514-517:62-80

3. Cahen L (198á) the Group of Stanley city (Jurassic superior and Wealdien of the interior of the Republic of Zaire):Revision of knowledge. Rapp.Ann.1981-1982, Dép. Géol. Min.Driven Roy. Afr. Hundred, Tervuren (Belgium), 73-91

4. Cahen L, Ferrand JJ, Haarsma MJF, Lepersonne J, Verbeek, T.(1959) Description of the Survey of Samba. Ann.Driven.roy. Afr.Hundred, Tervuren (Belgium), Series in 8, Sciences geological, 29

5. Cahen L, Ferrand JJ, Haarsma MJF, Lepersonne J, Verbeek T (1960) Description of the Survey of Dekese. Ann.Driven.roy. Afr.Hundred, Tervuren (Belgium), Series In-8 _, Sciences Geological, 34

6. Cahen L, Lepersonne J (1954) current State of knowledge relating to the mesozoïc series of the interior of Congo.Belgian Bull Ploughshare Géol.77:20-37

7. Cahen L, Lepersonne J (1978) Synthesis of knowledge relating to the Group (in the past Series) of Lukuga (Permian of Zaire). Ann.Driven.Roy.Belgian Congo, Tervuren (Belgium), series in-8, Sci. géol., 82, 115-152.

8. Chorowicz J, the Baker J, Makazu Mumbi M (1990) the Central Basin of Zaire:a Basin initiated in higher Protérozoïque.Contribution of the analysis of hydrographic network. C.R.Acad. Sci.Paris, t.311, Series II, 349-356.

9. Hake JP (1981) Paleontological study of the Esso/Texaco well Gilson-1, Zaire.Unpublishe dreport EPR-E.WA19.81

10. Hake JP (1994) Mesozoic-Cenozoic lacustrine sediments of the Zaire Interior Basin.In:Gierlowski-Kordesch E, Kelts K (eds) Total geological record of lake basins.Cambridge University Press, Cambridge, pp 31-36

11. Horn J (1911) On the possibility of the existence of oil reservoirs in Congo.Ann Ploughshare Géol. Belg.36(19101911):9-15

12. Crosby AG, Fishwick S, White N (2010) Structure and evolution of the intracratonic Congo Basin.Geochem Geophys Geosyst 11: Q06010.

13. Daly MC, Lawrence SR, Diemu-Thiband K, Matouana B (1992) Tectonic evolution of the central Basin.Zaire J Géol.Ploughshare Lond 149:539-546

14. Delvaux D (2001) Tectonic and paleostress evolution of the Tanganyika-Rukwa-Malawi rift segment, East African System Rift.In:Pa Ziegler, W Cavazza and AHF Robertson and S CrasquinSoleau, Eds. Peri-Tethys Memoir 6:PeriTethyan Rift/Wrench Basins and Passivates Margins. Mém.Driven.Natn.Hist.nat., 186: 545-567.Paris

15. Delvaux Damien and max Fernandez-Alonso (2015) CongoBasinChapter_18_Petroleum Potential

16. Delpomdor F, Linnemann U, Boven A, Gartner A, Travin A, Blanpied C, Hielsma H, Préat A (2013) Depositional age, source, tectonic and palaeoclimatic settings of the late Mesoproterozoic - middle Super Neoproterozoic Mbuji-Mayi group, Democratic Republic of Congo.Palaeogeogr Palaeoclimatol Palaeoecol 389:35-47

17. ECL (1988) Hydrocarbon potential of central Cuvette (Republic of Zaire).Exploration Limited Consultants, Oil Technical Cell, Pétrozaire, unpublished carryforward, 41 p.+ figures, tables, appendices and enclosures

18. Espitalié, J, Deroo, G, Marquis, F (198ä) pyrolysis Rock'n'roll-Eval and its applications. Oil \& Gas Science and Technology - Rev.IFP, 40, 5, 563-579.

19. Espitalié, J, Deroo, G, Marquis, F (1985b) pyrolysis Rock'n'roll-Eval and its applications. Oil \& Gas Science and Technology - Rev.IFP, 40, 6, 755-783.

20. ESSO Zaire limited liability company (1981a) Geological completion carryforward. Mbandaka-1.Unpublished carryforward

21. ESSO Zaire limited liability company (1981b) Geological completion carryforward. Gilson-1.Unpublished carryforward

22. Folco Laverdière, Anja Holstein, Laurent Thiebaut, Robert Mallee, Guillaume Gravejat, Benjamin Desclozeaux (1999) File coupling, principal methods of analysis in geochemistry.

23. Harriman G (2011) Geochemical review of the Central Basin. The hydrocarbon potential of the Central Basin, DRC.With review of existing geochemical one source rock'n'rolls and seeps dated.GH Geochem Ltd, carryforward GHG 2457, unpublished, $34 \mathrm{p}$

24. JNOC (1984) Report/ratio of the investigations geophysics and geological in the central Basin of the Republic of Zaire.National Japan Oil Corporation, Unpublished, 205p

25. Kadima E, Delvaux D, Sebagenzi SN, Tack L, Kabeya M (2011a) Structure and geological history of the Congo Basin:year integrated interpretation of gravity, magnetic and reflection seismic dated.Basin LMBO.23(5):499-527

26. Kadima EK, Sebagenzi S, Lucazeau F (2011b) A Proterozoic-rift origin for the structure and the evolution of the cratonic Congo Basin.Earth Planet Sci Lett 304:240-250 
27. Lafargue, E, Marquis, F, Pillot, D. (1998) Rock'n'roll-Eval 6 Applications in Hydrocarbon Exploration, Production and Soils Contamination Studies. Oil \& Gas Science and Technology - Rev.IFP, 53, 4, 421-437

28. Lawrence S, Makazu MM (1988) Zaïre' S Central basin.Prospectivity outlook.Oil Gas J 86(38): 105-108.

29. Lepersonne J (1974) Geological map of Zaire to the 1/2.000.000 and explanatory leaflet, Republic of Zaire, Direction of Geology, Kinshasa \&Mus. Roy.Afr.Centr, Tervuren

30. Lepersonne J (1977) Structure geological of the Inner basin of Zaire. Bull.Acad.Roy.Belg., Cl Sci., ëse' laugh, 63(12), 941-965, Brussels

31. Linol B (2013) Sedimentology and sequence stratigraphy of the Congo and Kalahari basins of South-Exchange Africa and to their evolution during the formation and breakup of West-Gondwana. pH.D. thesis Nelson Mandela Metropolitan University, South Africa, 370p.

32. Mello MR. (2008) Field survey, seep collection and HRGT analysis of seeps over CoMiCo exploration areas and samples correlation with Brazil, Africa and Middle-East.High Technology Resolution \& Petroleum (HRT), unpublished carryforward, 130p

33. Misser F (2013) Stakes and challenges of an oil province in becoming.In:Madrysse S, Omasonbo J (eds) Economic situations Congolaises 2012.Policy, mining sector and natural stock management in R.D. Congo.African Books 82, 147177.Royal museum of Central Africa and Harmattan, Paris.ISBN 978-2-343-00465-5.

34. Pilipili Mawezi J (2010) the oil of the democratic Republic of Congo.Southern Africa Resource Watch, Johannesburg, South Africa, p 133.

35. Sachse VF, Delvaux D, Littke R (2012) Petrological and geochemical investigations of potential source rock'n'rolls of the Central Congo Basin, DRC. AAPG Bull 96(2): 277-300.

36. Samira SAIFI (2012) Exposed on pyrolysis rock'n'roll-eval and its applications in organic geochemistry and the oil prospection.Department of the mining and oil layers University Me Hammed Bouguerra, Boumerdès, Algeria.

37. Scotese CR (2009) Late Proterozoic punt tectonics and palaeogeography: with of two supercontinents, Rodinia and Pannotia, Special Publications, flight 326 bruises.Geological Society, London, pp 67 - 83

38. Tavern L (197ä) In connection with three Téléostéens Salmoniformes of the Cretaceous inferior (Wealdien) of Zaire, previously of writings in the kinds Leptolepis and Culpavus (PiscesTeleostei).Rev Zool Afr 89:481-504

39. Tavern L (1975b) osteological Study of Leptolepiscaheni, Téléoste in fossil of the Jurassic superior (Kimméridgien) of Kisangani (be Stanleyville, Zaire) previously described in the Paraclupavus kind.Rev Zool Afr 89:821-853

40. Torsvik TH, Cocks LR (2011) The Palaeozoic palaeogeography of central Gondwana.In:Van Hinsbergen DJJ, Buiter SJH, Torsvik TH, Sheathed C, Webb SJ (eds) The formation and evolution of Africa:synopses of 3.8 Ga of Earth history havehas.Geological Society, London, pp 137-166, Special Publications

41. Vandenbroucke, Mr. (2003) Kerogen:from Standard to Models of Chemical Structure.Oil \& Gas Science and Technology - Rev.IFP, 58, 2, 243269.

42. Veatch AC (1935) Evolution of the Congo Basin.Mem Geol Ploughshare Am 3:184.

43. Verbeek T (1970) Geology and lithology of Lindien (Precambrian Superior of the north of the Democratic Republic of Congo). Ann.Driven.Roy.Afr.Hundred, Tervuren (Belgium), series in-8, Sci. géol., 66, 311 p 